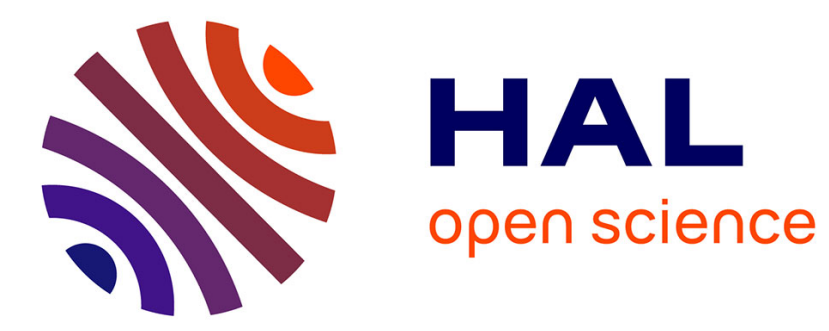

\title{
Tree root architecture: new insights from a comprehensive study on dikes
}

\author{
M. Vennetier, C. Zanetti, P. Mériaux, B. Mary
}

\section{To cite this version:}

M. Vennetier, C. Zanetti, P. Mériaux, B. Mary. Tree root architecture: new insights from a comprehensive study on dikes. Plant and Soil, 2015, pp.81-101. 10.1007/s11104-014-2272-9 . hal-01357095

\section{HAL Id: hal-01357095 \\ https://hal.science/hal-01357095}

Submitted on 29 Aug 2016

HAL is a multi-disciplinary open access archive for the deposit and dissemination of scientific research documents, whether they are published or not. The documents may come from teaching and research institutions in France or abroad, or from public or private research centers.
L'archive ouverte pluridisciplinaire HAL, est destinée au dépôt et à la diffusion de documents scientifiques de niveau recherche, publiés ou non, émanant des établissements d'enseignement et de recherche français ou étrangers, des laboratoires publics ou privés. 


\title{
Tree root architecture: new insights from a comprehensive study on dikes
}

\section{Authors:}

\author{
Michel VENNETIER ${ }^{*(1+2)}$, Caroline ZANETTI ${ }^{(3+1 . b)}$, Patrice MERIAUX ${ }^{(1 . b)}$, Benjamin MARY ${ }^{(1 . b+4)}$ \\ Michel VENNETIER *Corresponding author
}

(1a) Irstea, UR Ecosystèmes Méditerranéens et Risques, 3275 route Cézanne, CS 40061, 13182 Aix-en-Provence Cedex 5, France

(2) ECCOREV FR 3098, Université Aix-Marseille, France

Michel.vennetier@irstea.fr

Tél: +334426699 22, Fax:+ 33442668865

\section{Caroline ZANETTI}

(1b) Irstea, UR Ouvrages Hydrauliques et Hydrologie, 3275 route Cézanne, CS 40061, F- 13182 Aix-en-Provence Cedex 5, France

(3) Arbeausolutions: Pepinière d'Entreprises Innovantes, 100 impasse des Houillères, Le Pontet CS 50014, 13590 Meyreuil, France

c.zanetti@arbeausolutions.fr

\section{Patrice MERIAUX}

(1b) Irstea, UR Ouvrages Hydrauliques et Hydrologie, 3275 route Cézanne, CS 40061, F- 1318213182 Aix-en-Provence Cedex 5, France patrice.meriaux@irstea.fr

\author{
Benjamin MARY \\ (1b) Irstea, UR Ouvrages Hydrauliques et Hydrologie, \\ 3275 route Cézanne, CS 40061, F- 1318213182 Aix-en-Provence Cedex 5, France \\ (4) LABEX OT-Med, Europôle Méditerranéen de l'Arbois, \\ Bâtiment du CEREGE, BP 80, 13545 Aix-en-Provence Cedex 4, France \\ benjamin.mary@irstea.fr
}

\begin{abstract}
Aims

This study aimed at disentangling the respective influence of species, environment, root size and root type in tree root architecture.

Method

The root system of 106 adult trees from ten species was carefully extracted from French dikes. Root length and proximal diameter, length and diameter of root segments and branch insertion diameter were measured. Root branching and tapering rates, segment taper, classical $(\mathrm{P})$ and new architectural parameters related to branching patterns were computed.

Results

Two contrasting root types called "running" (R) and "short" (S), were identified from growth and architectural parameters. Compared to $\mathrm{S}$ roots, $\mathrm{R}$ roots were longer for an equivalent proximal diameter and singled out with lower tapering rate, branching rate and segment taper and with smaller branches. Their main axis lost less in diameter at branching point for branches of the same size. Tree species had little influence on these architectural parameters. The effect of soil material (coarse vs fine) was significant mainly on root size, on branching rate in fine material, and only secondarily on some branching patterns for running roots and on segment taper. The new architectural parameters describe branching patterns more accurately than classical ones.

Conclusion

This study provides an original insight in tree root architectural analysis, proposing a new root typology and innovative parameters for the description and modeling of root architecture.
\end{abstract}

\section{Key words:}

Tree root architecture; tapering rate; branching patterns; earth dike 


\section{1 - Introduction}

Root systems of ligneous plants are hierarchically and structurally organized and their study must rely on an architectural analysis and on root typologies. Existing root classifications and typologies are generally based on the global structure of root systems. They highlight determinisms generally considered as species-dependent (Atger 1991; Atger and Edelin 1994a; Collet et al. 2006; Köstler et al. 1968), and their plasticity according to environmental constraints (Fitter et al. 1991; Foussadier 2003). A precise assessment of tree root architecture requires the excavation of roots and even of whole root systems, which is costly and time consuming (Danjon and Reubens 2008; Smit et al. 2000). This is why most recent and detailed studies of tree root architecture concerned a reduced number of individuals or small and young trees (Danjon et al. 2005; Danjon et al. 2013b; Valdes-Rodriguez et al. 2013; Vercambre et al. 2003; Wagner et al. 2011), except after storms resulting in extensive windthrow (Nicoll et al. 2006b).

Measures allowing root architectural analysis can be manual (Dupuy 2005) or semi-automatic, using a magnetic 3-D digitizer (Danjon 2005; Nicoll et al. 2006a). These measures take time on large root systems, what makes it difficult to gather a representative sample of adult trees. When trees grow on homogeneous soils or substrates, root 3-D architecture can also be obtained by the measurement of some representative roots, and the reconstruction of the entire system using a developmental model (Collet et al. 2006; Danjon and Reubens 2008). However, this technique is not adapted to heterogeneous and constrained environments: in this case, a more functional-structural root system modeling is required, to account for functional tradeoffs between root foraging strategies and their dependence on contrasting resources distribution and availability (Dunbabin et al. 2013).

At the scale of individual roots, a classification was described by Fitter (1987) on the basis of branching patterns, distinguishing at both ends the "herringbones" and "dichotomous" types. Root architecture is the result of four main processes: (1) root length growth, (2) root diameter increase, (3) initial branching patterns at root tip during root elongation (Barthelemy and Caraglio 2007) and, (4) reiteration processes producing new ramifications on old roots (Atger and Edelin 1994b; Barthélémy et al. 1995). The fractal branching analysis enables characterizing the hierarchical and spatial relations between the ramifications within individual roots and to rebuild entire root systems from a limited number of measures (Fitter and Stickland 1992; Van Noordwijk et al. 1994): the root diameter before and after each ramification, the length of segments between ramifications and the number and diameter of branches per length unit. Ligneous roots are characterized not only by architectural patterns but also by their functional properties: roots ensure tree anchoring in the ground, the prospection of the environment, water and nutrient uptake and transportation, and the storage of reserves. Because constraints and resources can be unevenly distributed in the soil, and some resources far from the stump, roots may differ in length and branching patterns according to their position and main role.

Study goals

An architectural analysis was performed in order to disentangle the respective influence of tree species, root size and soil materials on individual-root growth and architectural patterns. We hypothesized that two contrasting types of roots, which can be sorted visually, could be statistically distinguished and that root architectural parameters depended on root size and type, and potentially on tree species. We tested two original architectural parameters, complementary to usual ones, which could help sorting these root types and improve the description and modelling of root functional architecture.

\section{2 - Material and Methods}

\section{1 - Choice of site and species}

For this study, we took advantage of a research program focusing on root system development in French earth dikes (Zanetti et al. 2014). Ten species, the most frequent on these dikes were studied. Eight at low elevation in valleys: poplar (Populus nigra L.), locust (Robinia pseudoacacia L.), oaks (Quercus pubescens Willd., Q. ilex L.), ash tree (Fraxinus excelsior L.), maples (Acer campestre L. and A. negundo L.), willow (Salix alba L.) and two in mountains around $1500 \mathrm{~m}$ : European larch (Larix decidua Mill.) and Scots pine (Pinus sylvestris L.). One hundred and six root systems from adult trees $(25-70 \mathrm{~cm}$ in diameter) growing on these dikes were excavated (Table 1). The sampling strategy took tree species, dike material (fine or coarse) and the position of trees on the fill (top, slope, toe) into account as each of these criteria can influence root system development and structure.

In a first step selected trees were cut at 1 meter from trunk base. The excavation process followed four steps: (1) superficial roots were bared and cleared out from trunk base towards the periphery, with a shovel and, when necessary, manually to minimize damages. When possible, root main axis was entirely extracted up to its end (diameter $\leq 2 \mathrm{~mm}$ ). If necessary to free deeper roots, superficial roots were tagged, cut and put aside for the measurements, (2) deeper roots were progressively excavated, (3) the stump was slowly lifted in a sling to observe, tag and free remaining deep and vertical roots and (4) the stump was finally fully uprooted and lifted. Once the stump was uprooted, the trunk was cut at soil level and the stump stored upside-down and roots cleaned from remaining soil material for measurements. 
Table 1: Studied sites, species, age and diameter at breast height (DBH) of studied trees.

\begin{tabular}{|c|c|c|c|c|c|c|}
\hline $\begin{array}{c}\text { River site } \\
\text { Longitude/Latitude }\end{array}$ & Year & $\begin{array}{l}\text { Type of } \\
\text { dike }\end{array}$ & tree number & Species* & $\begin{array}{c}\text { Tree age } \\
(\mathrm{min} / \mathrm{mean} / \mathrm{max})\end{array}$ & $\begin{array}{c}\text { DBH cm } \\
(\mathrm{min} / \mathrm{mean} / \mathrm{max})\end{array}$ \\
\hline $\begin{array}{c}\text { Rhône - Montélimar } \\
04^{\circ} 43^{\prime} \mathrm{E} / 4^{\circ} 32^{\prime} \mathrm{N}\end{array}$ & 2007 & Canal & 12 & $6 ; 7 ; 8 ; 9$ & $8 / 26 / 43$ & $11 / 26 / 40$ \\
\hline $\begin{array}{c}\text { Rhône - Lyon } \\
05^{\circ} 02^{\prime} \mathrm{E} / 45^{\circ} 48^{\prime} \mathrm{N}\end{array}$ & 2007 & Canal & 18 & $\begin{array}{c}1 ; 3 ; 6 ; 7 \\
9\end{array}$ & $10 / 35 / 63$ & $20 / 29 / 58$ \\
\hline $\begin{array}{l}\text { Durance - Pertuis } \\
05^{\circ} 30^{\prime} \mathrm{E} / 43^{\circ} 40^{\prime} \mathrm{N}\end{array}$ & 2007 & $\begin{array}{c}\text { Flood } \\
\text { protection }\end{array}$ & 5 & $6 ; 7$ & - & $37 / 70 / 130$ \\
\hline $\begin{array}{l}\text { Isère - Grenoble } \\
05^{\circ} 47^{\prime} \mathrm{E} / 45^{\circ} 11^{\prime} \mathrm{N}\end{array}$ & 2008 & $\begin{array}{c}\text { Flood } \\
\text { protection }\end{array}$ & 18 & $\begin{array}{c}3 ; 6 ; 7 ; 9 ; \\
10\end{array}$ & $8 / 25 / 49$ & $20 / 65 / 150$ \\
\hline $\begin{array}{l}\text { Loire - Cosne sur L. } \\
02^{\circ} 54^{\prime} \mathrm{E} / 47^{\circ} 24^{\prime} \mathrm{N}\end{array}$ & 2008 & $\begin{array}{c}\text { Flood } \\
\text { protection }\end{array}$ & 20 & $\begin{array}{l}2 ; 3 ; 6 ; 7 ; \\
\quad 9 ; 10\end{array}$ & $18 / 31 / 45$ & $24 / 62 / 120$ \\
\hline $\begin{array}{c}\text { Bieugne - Castérino } \\
07^{\circ} 31^{\prime} \mathrm{E} / 44^{\circ} 04^{\prime} \mathrm{N}\end{array}$ & 2009 & $\begin{array}{c}\text { Flood } \\
\text { protection }\end{array}$ & 6 & $4 ; 5$ & $46 / 62 / 71$ & $26 / 41 / 56$ \\
\hline $\begin{array}{c}\text { Rhône Donzère } \\
04^{\circ} 42^{\prime} \mathrm{E} / 4^{\circ} 27^{\prime} \mathrm{N}\end{array}$ & 2010 & $\begin{array}{c}\text { Flood } \\
\text { protection }\end{array}$ & 14 & $6 ; 9$ & $46 / 62 / 71$ & $26 / 41 / 56$ \\
\hline $\begin{array}{l}\text { Leysse-Chambery } \\
06^{\circ} 00^{\prime} \mathrm{E} / 45^{\circ} 35^{\prime} \mathrm{N}\end{array}$ & 2011 & $\begin{array}{l}\text { Flood } \\
\text { protection }\end{array}$ & 13 & $3 ; 9 ; 10$ & $12 / 25 / 35$ & $7 / 28 / 60$ \\
\hline \multicolumn{3}{|c|}{ Total } & 106 & All & $8 / 35 / 71$ & $7 / 45 / 150$ \\
\hline
\end{tabular}

*(1) Acer Campestre, (2) Acer Negundo, (3) Fraxinus excelsior, (4) Larix decidua, (5) Pinus Sylvestris, (6) Populus Nigra, (7) Quercus Pubescens, (8) Quercus Ilex, (9) Robinia pseudoacacia, (10) Salix alba

The texture of material collected in the excavation hole of each tree was analysed and could be clearly split into two types (Table 2): coarse (c) corresponding to predominantly stony and gravely materials, and fine (f) composed of more than $50 \%$ of sand, silt and clay in various proportion: see Zanetti et al. (2014) for details.

Table 2: Distribution of soil samples according to the percentage of fine elements, and resulting material type.

\begin{tabular}{l|ccccc}
$\%$ fine material & $<30 \%$ & $31-50 \%$ & $51-70 \%$ & $71-90 \%$ & $91-100 \%$ \\
\hline$\%$ of samples & $36 \%$ & $17 \%$ & $7 \%$ & $16 \%$ & $35 \%$ \\
\hline Material type & Coarse & Coarse & Fine & Fine & Fine
\end{tabular}

\section{2 - Root and root segment selection}

For each root system, we measured a representative sample of the main roots, their relative importance being determined at one meter from the stump. Sample size for each tree was not fixed in advance, because the number of primary roots (taproots and first order laterals) varied from 10 to more than 50 with a high variability in size, direction and depth, and their large branches from 50 to more than 250 . Five to fifteen primary roots were selected by system. The sampling plan was based on root diameter, root depth and angle with soil surface and root position on the stump. Roots were selected all around the stump or from upslope and downslope when relevant. A priority was given within similar roots to those which could be measured up to the smallest diameter.

According to the angle with soil surface, roots are commonly sorted in three classes by scientific literature: shallow (or superficial), oblique and vertical (Köstler et al. 1968; Smit and Bengough 2000). This classification was only used for sampling. When they existed, vertical roots growing just under the stump, often stemming from the first root which developed during seed germination and called taproots $(\mathrm{T})$, were systematically 
measured. When they were found as branches along horizontal or oblique roots, vertical roots not situated under the stump and usually called "sinkers" were selected among other representative branches, not measured systematically. On each selected primary root, representative branches of lower order were measured from their insertion point when it was possible. As a whole, a majority of measured roots were first order laterals and taproots (50\%), followed by branches of hierarchical order 2 and 3 (resp. $21 \%$ and $24 \%$ ) and in a smaller proportion order 4 and 5 (resp. 4\% and $1 \%$ ). Each measured root axis was divided into segments between branching points, considering only branches over $2 \mathrm{~mm}$ in diameter. The length, proximal and distal diameter were measured for each segment as well as the insertion diameter of each of their branch at branching point. When the choice was limited, small and medium root axes broken at least 30 to $40 \mathrm{~cm}$ respectively from their insertion point were measured. Root axes broken closer to their insertion point or damaged during excavation were not taken into account to compute tapering and branching rates.

As a whole, $1464 \mathrm{~m}$ of root axes were analysed, representing 5623 segments belonging to 1349 different roots from 106 trees (Table 3). 396 large to medium roots could be measured entirely from their insertion point to their end at $2 \mathrm{~mm}$ of diameter.

Table 3: Number of studied trees, roots, segments and total root length per species.

\begin{tabular}{c|cccc} 
& $\begin{array}{c}\text { Number of } \\
\text { trees }\end{array}$ & $\begin{array}{c}\text { Root } \\
\text { number }\end{array}$ & $\begin{array}{c}\text { Segment } \\
\text { number }\end{array}$ & $\begin{array}{c}\text { Total root } \\
\text { length }(\mathrm{m})\end{array}$ \\
\hline \hline Acer campestre & 3 & 33 & 140 & 33 \\
\hline Acer negundo & 5 & 37 & 160 & 28 \\
\hline Fraxinus excelsior & 20 & 282 & 1140 & 302 \\
\hline Larix decidua & 4 & 31 & 200 & 49 \\
\hline Pinus sylvestris & 2 & 46 & 253 & 67 \\
\hline Populus nigra & 22 & 292 & 1336 & 284 \\
\hline Quercus ilex & 2 & 52 & 75 & 42 \\
\hline Quercus pubescens & 15 & 145 & 553 & 130 \\
\hline Robinia pseudoacacia & 25 & 326 & 1318 & 405 \\
Salix alba & 8 & 105 & 448 & 124 \\
\hline \hline Total & 106 & 1349 & 5623 & 1464
\end{tabular}

\section{3 - Root and segment traits}

Roots proximal diameter and segment proximal diameter were split into three classes: "Big" (B : proximal diam $\geq 5 \mathrm{~cm})$, "Intermediate" (I : $5 \mathrm{~cm}>$ proximal diam $\geq 1 \mathrm{~cm})$ and "Little" $(\mathrm{L}: 1 \mathrm{~cm}>$ proximal diam $>0.2 \mathrm{~cm}) .{ }^{1}$

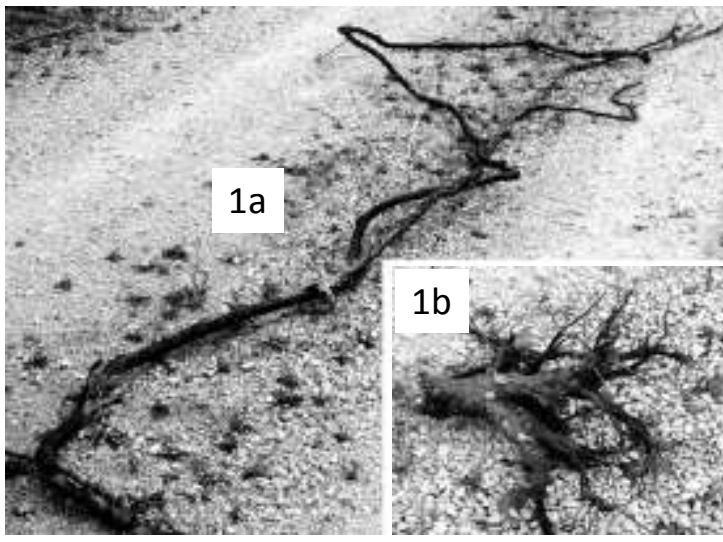

Fig. 1: two contrasting roots with the same proximal diameter from the same locust stump. 1a: running root $(R I)$. $1 b$ : short root $(S I)$

(Photos: Zanetti C.)
According to previous observations on uprooted trees (Zanetti et al. 2008), horizontal and oblique selected roots were visually classified into two types: Running roots (R) showing low tapering and branching rates (Fig. la) and Short roots $(\mathrm{S})$ with higher values for these two parameters (Fig. 1b).

The goal was to assess a possible uneven distribution of root parameters corresponding to two root morphological and functional types. As it was impossible to fix accurate limits between these two groups before having measured many roots and having studied most of the sites, and even to be sure that such types exist, classifying roots visually in the field relied subjectively on the relative values of both branching and tapering rates for each tree in each site.

\footnotetext{
${ }^{1}$ The name of root size classes and root types (Big vs Large, Little vs Small, Running vs Long, ... where chosen to prevent redundancies in the abbreviations ( $\mathrm{S}$ for small and short, $\mathrm{L}$ for large and long) when combining these two factors (see tables and figures).
} 
Vertical roots were considered separately, including taproots and sinkers $(\mathrm{T})$. These two categories were merged after the first analyses showing that there were no significant differences between them for any studied parameters.

Six variables related to root diameter and branching patterns were computed (Fig. 2):

Fig. 2: Architectural variables computed from root branching patterns.

$\emptyset P=$ proximal diameter,$\emptyset D=$ diameter of root distal extremity, $L=$ length of the measured part of the root, $D_{\text {bef. } n}$. or $D_{a f t . n}=$ diameter of the segment respectively just before or just after the branching point $n$, $D_{\text {ram.n }}=$ proximal diameter of branch $n$

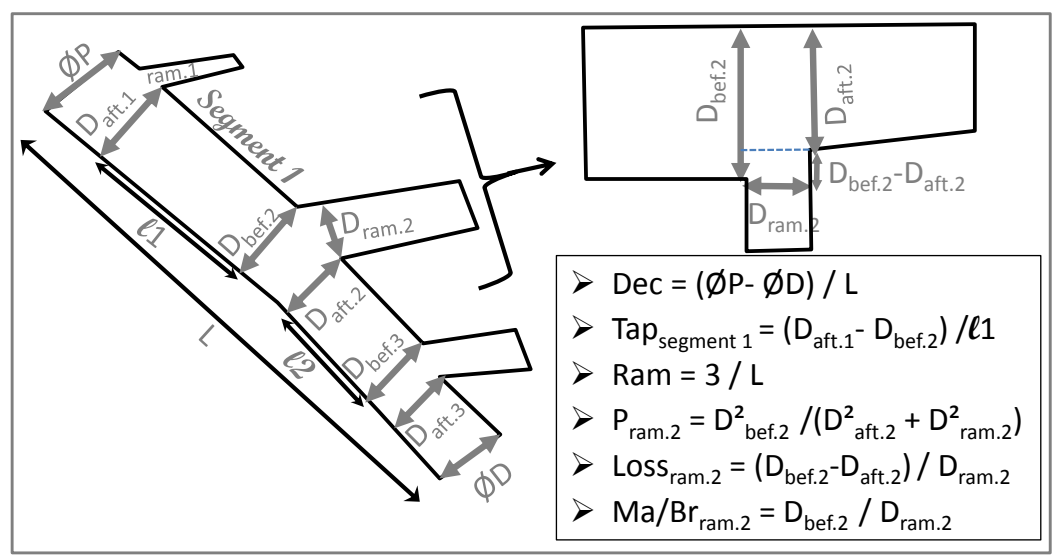

- Dec (whole-root diameter decrease rate $=$ root tapering rate, in $\mathrm{cm} / \mathrm{m}$ ): the tapering rate of a root on its whole length or on a measured part of it. Dec is a result of both segment taper between branching points and the loss of diameter of the mother axis at each branching point.

\section{Dec $=(\emptyset \mathbf{P}-\emptyset \mathrm{D}) / \mathrm{L}$}

$\emptyset \mathbf{P}$ is the proximal diameter, $\emptyset \mathbf{D}$ is the diameter of the distal extremity, $\mathbf{L}$ is the length of the measured part of the root.

- Tap (Segment taper, in $\mathrm{cm} / \mathrm{m}$ ): the decrease in diameter of a root segment between two branching points.

$$
\text { Tap }=\left(\mathbf{D}_{\text {aft.n-1- }} \mathbf{D}_{\text {bef.n }}\right) / \boldsymbol{l}
$$

$\mathbf{D}_{\text {aft.n-1 }}$ is the diameter after the branching point upside the segment, $\mathbf{D}_{\text {bef.n }}$ is the diameter before the next branching point downside the segment, $\boldsymbol{l}$ is the length of the segment between the two branching points.

Big primary roots and taproots sometimes presented an initial zone of very fast decreasing diameter, called zone of rapid taper - ZRT (Eis 1974; Wilson 1975). Because of its short length (10 to $50 \mathrm{~cm}$ ) and its high variability between different trees, due to their age, their position on dike fill, their lean and variations in wind speed and frequency patterns, we considered it separately and eliminated it from general analyses. Different quantitative definitions of ZRT are found in literature: they rely whether on a fixed segment taper rate threshold or on a distance to the stump proportional to tree diameter (Danjon 2005) or on fixed depth and radial distances from the main tree axis (Danjon et al. 1999a; Danjon et al. 1999b). These definitions would have obliged us to remove large parts of roots we considered as representative, and particularly small roots issued from the stump or from the taproot and presenting no individual ZRT, and many short roots (S type) with a high but regular taper rate. For these reasons, we defined the ZRT root by root as the first segments having a tapering rate more than $40 \%$ over the mean of the following segments, this mean value being computed on a length of at least $50 \mathrm{~cm}$. This definition eliminates only the first part of the root which is not representative of its mean architecture.

A ZRT was identified for 3\% of the roots (only on big roots), and accounted for $1.2 \%$ of measured segments. Mean ZRT length was $25 \mathrm{~cm}$, accounting for $8 \%$ of the length of concerned roots, and $0.9 \%$ of the total measured root length. The mean ZRT taper was $4.45 \mathrm{~cm} / \mathrm{m}$.

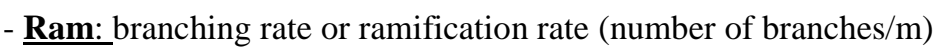

\section{$\operatorname{Ram}=\mathbf{n} \cdot \operatorname{Ram} / \mathbf{L}$}

$\mathrm{n}$. Ram is the total number of branches on the measured part of the root excluding fine roots $(<2 \mathrm{~mm}), \mathrm{L}$ is the corresponding root length

Branching rate was computed for only entire roots and root parts at least four times the average segment length for a given group of root type and size. This limit was chosen in order to prevent inaccurate low branching rates due to root axis with few segments and for which the last branching point may be missing. As a whole, 760 entire roots or sufficiently long broken roots were considered. 
$\underline{-\mathbf{P}}$ : the ratio between total root cross sectional area (CSA) before and after each ramification

(Soethe et al. 2007).

$$
\mathbf{P}=\mathbf{D}_{\text {bef }}^{2} /\left(\mathbf{D}_{\text {aft }}^{2}+\Sigma \mathbf{D}^{2}{ }_{\text {ram }}\right)
$$

$\mathrm{D}^{2}{ }_{\text {bef }}$ is related to the main axis CSA before a ramification point $\left(\mathrm{CSA}=\pi \mathrm{D}^{2} / 4\right), \mathrm{D}^{2}$ aft to the main axis CSA after the ramification point, $\Sigma \mathrm{D}_{\text {ram }}^{2}$ to the sum of branches CSAs.

A P factor greater (or smaller) than 1 corresponds respectively to a total CSA decrease (or increase) at each ramification point.

- ØLoss (or $\emptyset^{2}$ Loss) the ratio between the diameter loss (respectively CSA loss) for the main axis at a branching point and the sum of branches diameters (respectively branches CSA).

$$
\begin{aligned}
& \varnothing \text { Loss }=\left(D_{\text {bef }}-D_{\text {aft }}\right)_{\text {main axis }} / \Sigma D_{\text {ram }} \\
& \emptyset^{2} \text { Loss }=\left(D_{\text {bef }^{2}}-D^{2}{ }_{\text {aft }}\right)_{\text {main axis }} / \Sigma D^{2}{ }_{\text {ram }}
\end{aligned}
$$

This original variable was tested to study the influence of branch size on the variation of main axis diameter or CSA at each ramification point. A higher ØLoss corresponds to a sharper decrease of the main axis diameter at a ramification point for a given diameter (or sum of diameters) of branches at this point.

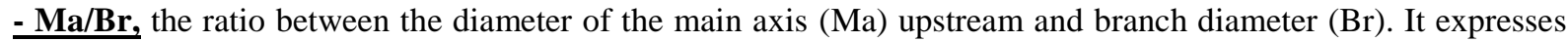
the relative size of branches compared with the main axis. It can be computed with the sum of branches diameters $(\mathrm{Ma} / \mathrm{Br})$ or with the diameter of the biggest branch $\left(\mathrm{Ma} / \mathrm{Br}_{\max }\right)$ when multiple branching occurs at the same point. It can also be calculated only for the segments with a single branch $\left(\mathrm{Ma} / \mathrm{Br}_{\text {sing }}\right)$ for a better coherence, as multiple branching at a given point can be the result of the aggregation of initially separated ramifications, due to branch diameter increase with age.

$$
\begin{aligned}
& \mathrm{Ma} / \mathrm{Br}=\mathrm{D}_{\text {bef }} / \Sigma \mathrm{D}_{\text {branch }} \\
& \mathrm{Ma} / \mathrm{Br}_{\text {max }}=\mathrm{D}_{\text {bef }} / \mathrm{Dmax}_{\text {branch }} \\
& \mathrm{Ma} / \mathrm{Br}_{\text {sing }}=\mathrm{D}_{\text {bef }} / \mathrm{D}_{\text {single branch }}
\end{aligned}
$$

Although they are weakly correlated, $\mathrm{P}, \varnothing$ Loss and $\mathrm{Ma} / \mathrm{Br}$ express three different and complementary relations between branches and their mother axis, the three ratios being functionally independent.

In contrast to $\mathrm{P}$, which is independent from the diameter ratio between a root main axis and its branches, ØLoss is strongly related to this ratio, and describes an important characteristic of branching patterns. Compared to $\varnothing$ Loss, for which no hypothesis on branch size is required, $\mathrm{Ma} / \mathrm{Br}$ adds supplementary information on the ratio between main axis before ramification and branch diameter, independently from the relative impact of each branch on the main axis. A higher $\mathrm{Ma} / \mathrm{Br}$ ratio means that for a given diameter of the main axis upstream, the diameter of branches is proportionally smaller. This does not mean that the $\mathrm{P}$ factor is higher, as smaller branches (high $\mathrm{Ma} / \mathrm{Br}$ ) can be compensated by a smaller relative decrease of the main axis (low ØLoss). Therefore, a variation of $\mathrm{P}$ can be due to independent and complementary variations of $\varnothing \mathrm{Loss}$ and $\mathrm{Ma} / \mathrm{Br}$, which cannot be derived separately from the initial $\mathrm{P}$ ratio.

In order to prevent inaccurate values of root tapering and branching rates from very short broken roots, these two variables were computed only for roots and root parts at least 2 and 4 times respectively the average segment length for a given group of root type and size. As a whole, 1122 and 760 roots were considered to compute Dec and Ram respectively.

Segment taper was computed on 4301 segments after exclusion of ZRTs and of very short segments (shorter than $5 \mathrm{~cm}$ for little and intermediate roots and $7 \mathrm{~cm}$ for big ones). These limits were chosen to eliminate possible discrepancies due to the deformation of roots close to branching point.

We computed $\mathrm{P}, \varnothing$ Loss and $\mathrm{Ma} / \mathrm{Br}$ for 3345 segments presenting at least one ramification and not included in a ZRT. These segments belong for respectively 30,35 and $35 \%$ to segment classes S, I and B, which is well balanced, and for 18,31 and $51 \%$ to roots of classes S, I and B, the number of segments per measured root increasing logically with roots diameter.

\section{4 - Statistical evaluation}

We first studied the role of species compared to other factors in the variability of architectural parameters with two kinds of multivariate analyses (1): we used a redundancy analysis (RDA) to separate the relative impact of soil material, root or root segment characteristics (size and type) and species and their interactions with both variance partitioning analysis and Monte Carlo permutation tests, synthesized through Venn diagrams; (2) we computed a multiple correspondence analysis (CA) with all architectural parameters in classes of equal numbers along with qualitative variables: material (fine or coarse), root types (T, S, R), root size (B, I, L) or segment size (6 classes) and species (8 species). RDA and CA were performed for both roots and root segments. In addition, Kruskall-Wallis tests were computed to analyze differences between species for each root or segment architectural parameter, followed in case of significant difference by a Nemenyi test (1963) to assess differences by pairs. As four of the studied species were found only on one type of material, fine (maple and Salix alba) or 
coarse (larch and Scots pine), these species were compared to others first on all material types and then only on the concerned material.

We computed the distribution of tapering and branching rates for all roots in order to determine if the classification in $\mathrm{S}$ and $\mathrm{R}$ types corresponded solely to the two ends of a continuous distribution or to contrasting classes with a bimodal distribution. For this analysis, and not for others, root tapering rate values were centered by tree before computing values distribution in order to factor out the possible influence of species, sites and tree size. To validate root tapering and root length analyses, we processed separately the 396 unbroken roots measured up to their extremity.

We studied the stability of architectural parameters across hierarchical orders: for each measured root axis classified in $\mathrm{S}$ or $\mathrm{R}$ type, we counted the branches of the same type and those of the other type.

All architectural variables were analyzed for the main parameters: species, root type, root size and material type of the studied site. The last three parameters were first studied separately and then crossed by two and three to study their interactions. In the following text, tables and figures, root groups are named with three letters: root type and root size in capital letters and material in small letter after a dot. For example root groups noted "S", "L", "TI", "RB.f", "SL.c" correspond respectively to the following groups: all short roots (all sizes and materials together), all little roots (all root types and materials together), taproots with intermediate diameter (all materials together), running big roots on fine material, and short little roots on coarse material.

Because most data did not fit the normal distribution, two non-parametric tests were used to compare groups: Kruskal-Wallis test for the comparison of multiple groups, and in case of significant difference Nemenyi test (1963) for a global assessment of differences by pairs. As Nemenyi test is highly responsive to the number of observations per group and to the number of groups, groups with less than 25 values were not taken into account. For all analyses, small TL (6 observations) were nearly missing as we worked only with adult trees. For analyses dealing with segments (variables $=\mathrm{P}, \varnothing$ Loss and $\mathrm{Ma} / \mathrm{Br}$ ), the numbers of TI.c (16), TL (6), TL.c (5) and TL.f (1) were under the limit.

All analyses were computed with R software (R Core Team 2010).

\section{3 - RESULTS}

\section{1 - Variability between species}

In the RDA analysis on roots, root size and type explained $30.2 \%$ of the variance of architectural parameters and accounted for $98.2 \%$ of the explained variance, this share being highly significant (Figure 3a). Species and material together accounted for $1.5 \%$ of the total variance and $5 \%$ of the explained variance. Most of the share of variance explained by species was included in the interaction between species and root characteristics, while material-root interaction was weak. In the RDA for root segments, the share of explained variance related to root characteristics was equivalent (98\%), but species and material accounted each for only $1 \%$, with no interactions with root characteristics.

Figure 3: multivariate analyses with all variables and species - RDA (3a) and AFC (3b).

3a: Partition of explained variance by the RDA for root architectural parameters (Dec, mean segment taper, Ram). Circle areas are proportional to the percentage of explained variance by respectively species (Sp.), Material (Mat) and root type $(T, S, R)$ and size $(B, I$, $L)$. The relative intersection between circles is proportional to variance explained by the interaction between concerned factors.
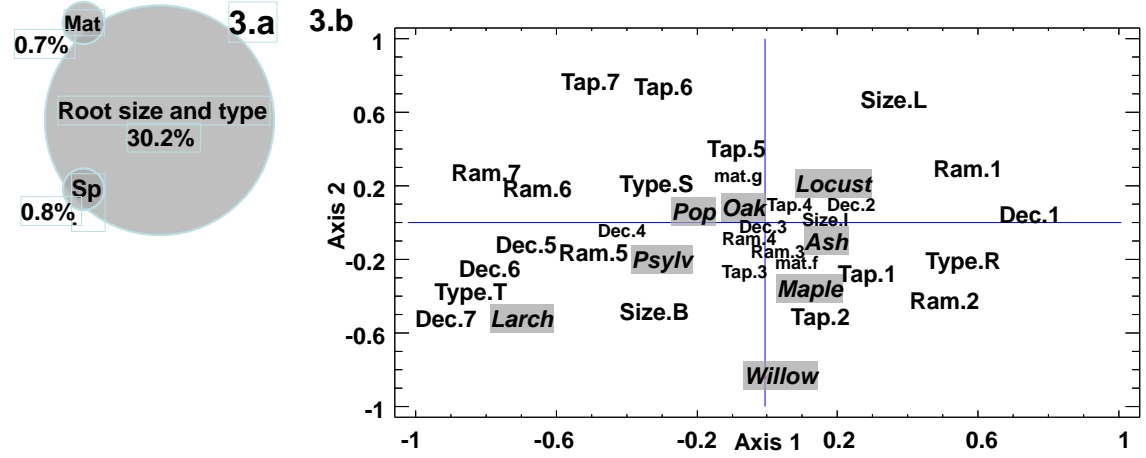

3b: First plane of the correspondence analysis on root architectural parameters. Species are highlighted in grey: Pop is Poplar, Psylv is Scots pine. For root size, B is big, I is intermediate and L is little. For Root types, $T$ is taproots, $S$ is Short roots, $R$ is running roots. Root tapering rate (Dec), root branching rate (Ram) and root mean segment taper (Tap) are split in classes of equal numbers from 1 to 7 from the lowest to the highest values.

Consistently with the low weight of species in RDA analyses, the main species (poplar, locust, oak, maple and ash) representing $85 \%$ of the roots and segments, were grouped together close to the middle of the plane in the PCA analyses (Figure 3b). In the CA for roots, the contribution of each species to the first two axes was extremely low (1.1\% for the best), 10 times less than the contributions of the most important variables: axis one was determined by root tapering and ramification rates and by root types, axis two by root mean segment taper 
and root size. Material was not significantly represented in this plane. Only two species were significantly linked to the first three axes, respectively larch on axes 1 and 3 and willow on axis 2. Maple and willow mainly and to a lesser extent poplar contributed significantly to axis 4 , but with a weight however twice smaller than material which was the main determinant of this axis. Similar results were obtained for the CA on segments.

The low weight of species in root architectural parameters was confirmed by Nemenyi tests as detailed in the following paragraphs for each of these parameters. It was very clearly demonstrated when the relative variations of these parameters according to root size and type were compared to their variations between species (fig. 5 vs fig. 6). In accordance with the strong interaction between species and root characteristics, nearly none of the differences between species were consistent or significant across root size or type or on both materials. Therefore, all species were merged in analyses of root architectural parameters by root size and type and by material.

\section{2 - Root types: running vs short roots and taproots.}

The three root types (L, S and T) appeared clearly different for branching rate (Fig. 4.a). Nearly $85 \%$ of R roots had less than 4 branches/m, compared to respectively $22 \%$ and $16 \%$ for $\mathrm{S}$ and $\mathrm{T}$ roots.

For tapering rate, a logarithmic transformation separated the three root types (Fig. 4.b), the peaks of $\mathrm{R}$ and $\mathrm{S}$ roots being distinct. $R$ roots were limited to low values mainly between 0 and $2 \mathrm{~cm} / \mathrm{m}$, with less than $5 \%$ of values over $4 \mathrm{~cm} / \mathrm{m}$. Conversely, $S$ roots had their first peak between 2 and $4 \mathrm{~cm} / \mathrm{m}$ and a majority of values over $4 \mathrm{~cm} / \mathrm{m}$. T roots displayed a plateau between 2 and $4 \mathrm{~cm} / \mathrm{m}$ and several peaks at higher values. For tapering rate as for branching rate, $\mathrm{T}$ roots shared the first peak with $\mathrm{S}$ roots.

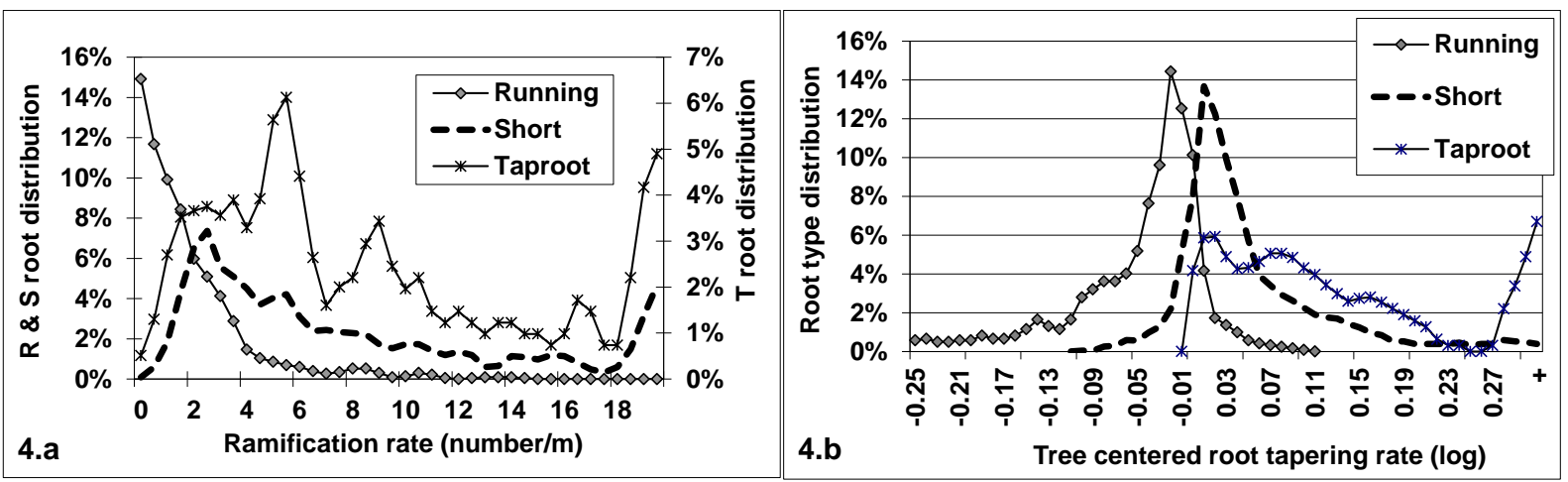

Fig. 4: Comparison of the frequency distribution of branching rate and root tapering rate for root types.

4.a: Distribution in percentage of branching rate for the three root types.

4.b: Distribution in percentage of tree-centred tapering rate values (log) for the three root types.

As the visual assessment of root types seemed to be consistent with the distribution of their main architectural patterns, these types were taken into account in further analyses.

Root main axis always kept the same type on its whole length. Moreover, $71 \%$ and $82 \%$ of the branches were of the same type than their mother axis for $\mathrm{S}$ and $\mathrm{R}$ roots respectively. The proportion of branches of the same type than the mother axis decreased when root diameter increased, with respectively $84 \%, 79 \%$ and $71 \%$ for $\mathrm{L}, \mathrm{I}$ and $\mathrm{B}$ roots. These proportions were consistently lower for big and intermediate $\mathrm{S}$ roots than for R roots of the same diameter classes. There was no discernible distribution pattern of $\mathrm{S}$ branches on $\mathrm{R}$ mother axes while intermediate or small $\mathrm{R}$ branches appeared on $\mathrm{S}$ roots rather towards their distal and proximal extremity.

\section{3 - Root length and diameter}

For a given proximal diameter, $\mathrm{S}$ roots had the same length whatever the material, whereas $\mathrm{R}$ roots were significantly longer on coarse material, indicating a smaller tapering rate, the difference being all the more important in percentage than the diameter was small (Table 4). With equivalent proximal diameters, $\mathrm{R}$ roots were twice to three times longer than $\mathrm{S}$ roots. Big $\mathrm{R}$ roots frequently reached 7 meters in length and sometimes much more. $\mathrm{S}$ roots rarely exceeded 3 meters. The relative difference in length between $\mathrm{S}$ and $\mathrm{R}$ roots was far higher in coarse $(65 \%)$ than in fine material $(45 \%)$.

Root mean diameter in our sample was not significantly different between coarse and fine material (7.9 vs 6.8 $\mathrm{cm}, \mathrm{P}=0.40)$ as well as between $\mathrm{R}$ and $\mathrm{S}$ roots $(6.55 \mathrm{vs} 6.59 \mathrm{~cm})$. Thus none of the differences found thereafter between $\mathrm{S}$ and $\mathrm{R}$ roots could be attributed to a difference in root diameter. But root diameter was larger for $\mathrm{T}$ roots $(13.6 \mathrm{~cm})$ due to the fact that big taproots are far more numerous than intermediate and little ones, while big and intermediate classes are balanced in numbers for $\mathrm{R}$ and $\mathrm{S}$ roots. Some of the differences between taproots and other roots had to be interpreted according to their larger mean diameter, and some analyses were computed with and without the larger taproots, particularly when taproots were compared to short roots. 
Among species, mean root diameter was significantly higher for larch, Scots pine and willow than for all other species. This difference was reduced, although still significant, for larch and Scots pine when the comparison was limited to coarse material. It must be kept in mind that these two species are underrepresented (respectively 4 and 2 trees). The difference was accentuated on fine material for willow. On coarse material, locust had smaller roots than poplars, mainly because of a far lower number of very big ones. These differences, partly explaining the interaction between species and root characteristics (Fig. 3a), had to be considered to interpret the analyses of architectural variables.

For all following results dealing with root tapering and branching rates and with segment taper, table $\mathrm{A}$ in annex gives the details of all statistical tests for roots split in sub-groups by the crossing of root type, root size and materials.

Table 4: Comparison of root lengths according to their type and size, all material together (upper part of the table, groups sharing the same letter do not differ significantly) and per material (lower part, with probability of the difference between fine and coarse material, NS = non-significant). Mean values are computed with the roots measured up to their extremity. Material types $(c=$ coarse, $f=$ fine $)$, root size $(B=$ big, $I=$ intermediate and $L=$ little), root types ( $T=$ taproots, $S=$ shorts roots and $R=$ running roots).

\begin{tabular}{l|ccccccc} 
& RB & RI & RL & SB & SI & SL & TB \\
\hline Mean Length for all materials & 273.4 & 135.1 & 90.9 & 103.3 & 61.7 & 43.1 & 99.5 \\
\multicolumn{1}{c}{ Comparison } & $\mathrm{a}$ & $\mathrm{b}$ & $\mathrm{c}$ & $\mathrm{c}$ & $\mathrm{d}$ & $\mathrm{d}$ & $\mathrm{cd}$ \\
\hline \hline Mean length on fine material (f) & 228.5 & 106.0 & 72.7 & 113.1 & 60.3 & 44.3 & 92.2 \\
Mean length on coarse material (c) & 333.3 & 173.8 & 139.3 & 95.2 & 62.5 & 41.4 & 105.5 \\
Probability (f vs c) & $<10^{-3}$ & $<10^{-3}$ & $<10^{-2}$ & $\mathrm{NS}$ & $\mathrm{NS}$ & $\mathrm{NS}$ & $\mathrm{NS}$ \\
Relative difference (c-f)/f & 0.46 & 0.64 & 0.92 & -0.16 & 0.04 & -0.07 & 0.14 \\
\hline
\end{tabular}

\section{4 - Root tapering rate (Dec)}

After elimination of the ZRT, root tapering rate regularly fell with root proximal diameter $\left(\mathrm{r}^{2}=0.53\right)$. The differences were significant between big and intermediate ones $(60 \%, \mathrm{P}<0.001)$, as well as between intermediate and little ones $(50 \%, \mathrm{P}<0.001)$. These differences by size remained significant when roots were sorted by type (Fig 5.a) or by material $(\mathrm{P}<0.01)$ and by combinations of type and material $(\mathrm{P}<0.05$, Table A).

Although root tapering rate was higher in fine than in coarse material, the difference was not significant globally, nor by root size or root type $(\mathrm{P}>0.2)$ nor for any combination of root size and type $(\mathrm{P}>0.1)$.

Taproots showed a significantly higher tapering rate than $S$ roots $(4.7$ vs $4.0 \mathrm{~cm} / \mathrm{m})$. This difference was explained by the difference in the average diameter between these two types. For I and L classes (Fig. 5a), and when the biggest taproots were set apart so that TB and SB roots had the same mean diameter, $\mathrm{T}$ and $\mathrm{S}$ roots had similar tapering rates. $\mathrm{S}$ and $\mathrm{T}$ roots together had higher tapering rates than $\mathrm{R}$ roots globally $(4.0 \mathrm{vs} 0.96 \mathrm{~cm} / \mathrm{m})$ as well as by size classes and material (Table A).

Among species (Fig. 6a), larch had a significantly higher root tapering rate than all broadleaved species, and willow as well as Scots pine a higher rate than locust and ash. But these results were clearly related to the difference in mean root diameter between species, as they were no longer significant when limited to I and L roots.

\section{5 - Branching rate}

Branching rate was inversely proportional to root diameter: it was significantly higher for little roots $(7.07 / \mathrm{m})$ than for intermediate $(5.95 / \mathrm{m})$ and big roots $(5.02 / \mathrm{m}$ without taproots, $6.10 / \mathrm{m}$ with taproots) which were not different. This difference by size remained among root types (Fig. 5.b) but was only significant between RL and RB. It was confirmed on fine material, not on coarse material (Fig. 7).

Branching rate was not different between fine and coarse material $(5.91 / \mathrm{m}$ vs $5.62 / \mathrm{m}, \mathrm{P}=0.46)$. No significant differences between materials appeared between groups sorted by root type or size (Table A and Fig 7).

The branching rate was 100 to $150 \%$ higher for $\mathrm{S}$ and $\mathrm{T}$ roots than for $\mathrm{R}$ roots. This difference was significant globally as well as by size and material (Fig. 5.b, Table A). The difference between $\mathrm{R}$ and $\mathrm{S}$ roots for both branching and tapering rates is highlighted in Fig. 7. Conversely $\mathrm{S}$ and $\mathrm{T}$ roots were very close for similar size and material and were never significantly different, globally or for any sub-group. The larger average size of TB compared to SB explains their distance in figure 7.

As for root tapering, branching rate was significantly different between larch or Scots pine and some broadleaved species (Fig 6.b), but these differences linked to mean root diameter disappeared for I and L roots. The only significant difference which was consistent across root types and size and on both materials was the higher branching rate of poplar compared to locust. 


\section{6 - Segment taper}

Segment taper was positively correlated to segment proximal diameter $\left(\mathrm{R}^{2}=0.27, \mathrm{P}<0.01\right)$. It was significantly different $(\mathrm{P}<0.01$, Table 5) between all classes of segment size or root size. The sign of these differences between size classes didn't change when root were sorted by types or by type and material, although not all the differences between sub-groups were significant (Fig. 5.c). Segment taper was slightly but significantly higher on fine than on coarse material (Table 5). When roots were grouped by size and types, significant differences between materials appeared only for R roots (table A). It was far smaller for R roots than for the two other root types. $\mathrm{S}$ and $\mathrm{T}$ roots differed significantly as a whole, but not when compared with a sample of equal mean diameter $(\mathrm{T}$ vs $\mathrm{S}$ taper $=1.8$ vs $1.7, \mathrm{P}=0.8$ ). Oak had globally a significantly higher segment taper than most other species (Fig 6.c), but only the differences with ash and locust were consistent for a majority of root types and size classes and on both materials.

Table 5: Segment taper $(\mathrm{cm} / \mathrm{m})$ according to separately Material types $(c=$ coarse, $f=$ fine $)$, root size $(B=$ big, $I$ $=$ intermediate, $L=$ little), root types $(T=$ taproots, $S=$ shorts roots, $R=$ running roots). Groups with different letters within the same category (size, material, type) differ significantly.

\begin{tabular}{|c|c|c|c|c|c|c|c|c|}
\hline type & B & I & $\mathrm{L}$ & $\mathrm{f}$ & c & $\mathrm{T}$ & $\mathrm{S}$ & $\mathrm{R}$ \\
\hline Mean $(\mathrm{cm} / \mathrm{m})$ & 2.60 & 1.21 & 0.71 & 1.67 & 1.42 & 2.2 & 1.7 & 0.71 \\
\hline $\mathrm{P}$ & & $\mathrm{b}$ & C & $a$ & $\mathrm{~b}$ & $a$ & $\mathrm{~b}$ & C \\
\hline
\end{tabular}

\section{7 - Relations between branches and main axis (P, ØLoss, MA/br)}

Table 6 presents the variations of $\mathrm{P}, \varnothing \mathrm{Loss}$ and MA/br with root size, root type and material.

Tables $\mathrm{B}(\mathrm{a}-\mathrm{b}-\mathrm{c})$ in annex present the complete set of statistical analyses for these variables and their variants $\left(\varnothing^{2} \mathrm{Loss}, \mathrm{Ma} / \mathrm{Br}_{\max }, \mathrm{Ma} / \mathrm{Br}_{\text {sing) }}\right.$ when roots are sorted in sub-groups by the different combination of the three explanatory factors. All results below refer to tables 6 and $\mathrm{B}$.

* For root size

All variables were significantly and positively correlated with root size, and the three root size classes differed for all variables $(\mathrm{B}>\mathrm{I}>\mathrm{L}$ ), except big and intermediate roots for $\varnothing$ Loss. When root size classes were split by material, or by type, or by type and material, their ranks was preserved. Most of the differences between size classes remained significant for sub-groups on coarse materials, although differences between $\mathrm{R}$ roots and the two other types by size were mainly preserved for $\varnothing$ Loss and $\varnothing^{2}$ Loss. On fine materials, differences remained significant mainly for $\mathrm{Ma} / \mathrm{Br}_{\max }$ and $\mathrm{Ma} / \mathrm{Br}_{\text {sing. }}$.

* For materials

Roots on coarse materials had slightly but significantly smaller values than those extracted from fine materials for $\mathrm{P}, \varnothing$ Loss and $\varnothing^{2}$ Loss but they did not differ for any variant of $\mathrm{Ma} / \mathrm{Br}$. Within root size classes some significant differences remained between material for big roots, and appeared for $\mathrm{Ma} / \mathrm{Br}$ and its variants, but with opposite signs between classes. Within root types, the only significant differences between materials were found with $\mathrm{R}$ roots for $\mathrm{P}$ and ØLoss.

* For root types

$\mathrm{R}$ roots differed from $\mathrm{T}$ and $\mathrm{S}$ roots for all variables, with lower values for $\mathrm{P}, \varnothing$ Loss and $\emptyset^{2}$ Loss and higher values for all variants of $\mathrm{Ma} / \mathrm{Br}$. No difference was found between $\mathrm{T}$ and $\mathrm{S}$ roots, except for $\mathrm{Ma} / \mathrm{Br}_{\text {sing }}$ which showed higher values for taproots. When root types were split by material or by size, differences between $\mathrm{R}$ roots and other types remain significant for most of the variants of $\varnothing \mathrm{Loss}$ and $\mathrm{Ma} / \mathrm{Br}$, but not for $\mathrm{P}$.

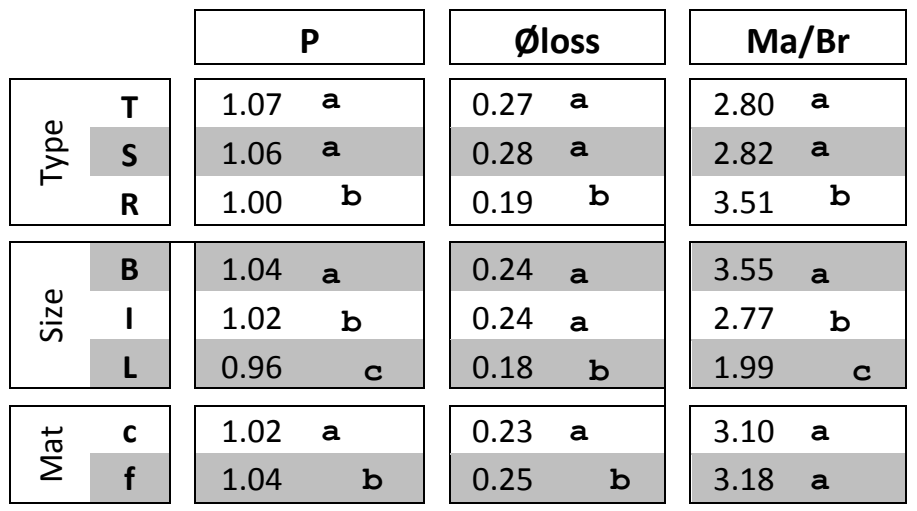

Table 6: Comparison of the mean values for all architectural variables describing and quantifying branching patterns for the Material types ( $c=$ coarse, $f=$ fine), root size ( $B=$ big, $I=$ intermediate, $L=$ little $)$, root types ( $T=$ taproots, $S=$ shorts roots, $R$ $=$ running roots). and their combinations by two or three. Groups sharing the same letter for each test did not differ significantly according to the Nemenyi test. 


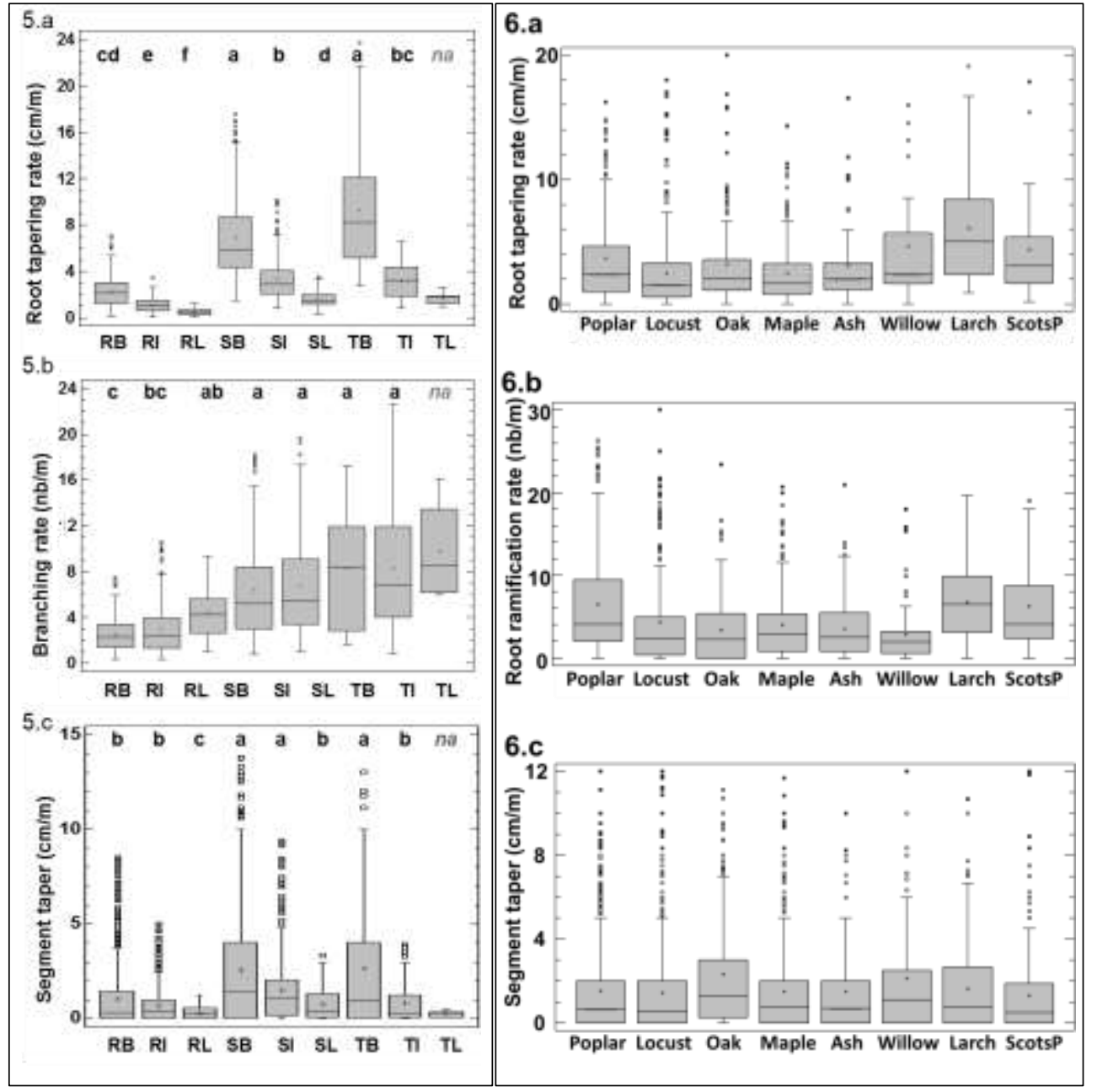

Fig. 5: differences between root type and size for architectural parameters. Rectangles delimit two central quartiles separated by the median, crosses indicate the mean, bars show distribution limits and dots are outliers. Groups sharing the same letter did not differ significantly.

5.a: Root tapering rate by root type and size.

$5 . b$ Branching rate by root type and size.

5.c Segment taper by root type and size
Fig. 6: differences between species for architectural parameters, all roots together. Rectangles delimit two central quartiles separated by the median, crosses indicate the mean, bars show distribution limits and dots are outliers.

6.a: Whole-root tapering rate by species.

$6 . b$ Branching rate by species

6.c Mean segment taper by species.

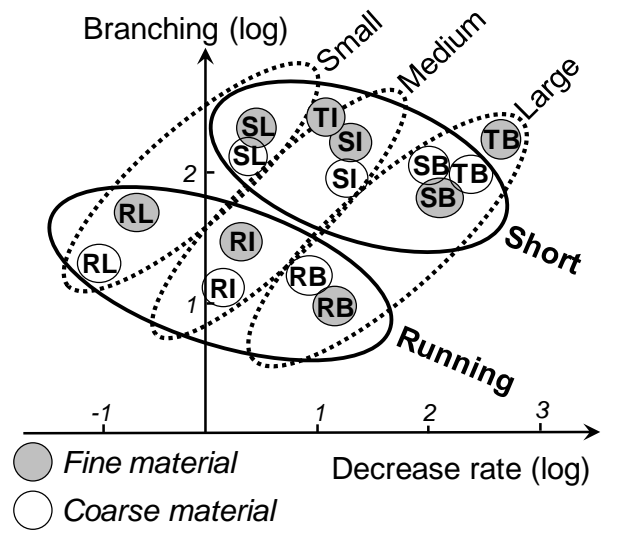

Fig. 7: Branching vs tapering rate (log scales) for groups of root type, size and material, all species together. 


\section{4 - DISCUSSION}

\section{1 - Tree species}

It was surprising that few significant differences were found between species for studied parameters. However, as clearly shown in figure 3, these parameters are mainly related to root size and type, and should be linked to root functions. The same functions may lead to the same morphological traits whatever the species, particularly because, in this study, we focused on only two homogeneous soil materials with no extreme constraints. The response of tree species in more heterogeneous conditions or with severe constraints (severe hydromorphy, extreme $\mathrm{pH}$ or hard rock layers) may have been more contrasting due to their specific adaptation to these chemical or physical constraints (Wahid 2000). Moreover, most of the differences found between species were at least partly explained by differences in their mean root diameter in our sample, particularly the larger roots of willow and larch compared to all other species, and to a lesser extent the larger roots of poplar and oak compared to locust and ash. The overlapping (interaction) between root characteristics and species in figure 3 is linked to these differences. Therefore, the following discussion focusses mainly on the relations between root architectural parameters, root size and type and material.

\section{2 - Root types}

Two main distinctive types of roots (Running roots - R / Short roots - S) seem to be differentiated by a wealth of growth and architectural parameters as well as by their response, for some of the architectural parameters, to environmental conditions as soil material. As discussed later, $\mathrm{T}$ roots could be included in the $\mathrm{S}$ type. The significant correlation with root size for both tapering and branching rates (Fig. 5 and 7) explains the overlapping between $\mathrm{R}$ and $\mathrm{S}$ roots in figure 4: big running roots overlap with little $\mathrm{S}$ roots.

In this study, these two types are independent from usual root typologies which differentiate whether (a) taproots, sinkers, oblique and shallow roots, according to their position on the stump and their angle with soil surface (Köstler et al. 1968; Sutton and Tinus 1983) or (b) herringbone vs dichotomous development according to branching patterns (Fitter 1987). This confirms the recent statement by Bodner et al. (2013), showing that root morphology is the most promising basis for root system classification, present measurement protocols being able to capture details of root diversity with architectural measurement.

Running roots are different from $\mathrm{S}$ roots, showing significantly lower values for root branching and tapering rates and segment taper, as well as for the three ratios quantifying the connections between root axis and its branches. Thus, the root tapering rate which is globally lower for $\mathrm{R}$ roots than for $\mathrm{S}$ roots entails several complementary explanations: branches are more spaced out what limits globally the variation in the diameter of mother axes linked to branching points, they loose less in diameter between each ramification (lower segment taper), they loose relatively less diameter for a given branch diameter (lower ØLoss), and the branches are as an average relatively smaller compared to the main axis (higher $\mathrm{Ma} / \mathrm{Br}$ ), which also limit the mean loss of diameter at each ramification point. The lower $\mathrm{P}$ ratio of $\mathrm{R}$ roots is explained by both the higher $\mathrm{Ma} / \mathrm{Br}$ and the lower $\varnothing$ Loss.

Surprisingly, the relative contribution of segment taper compared to that of ramification patterns in the wholeroot tapering rate is lower for $\mathrm{S}$ roots (40\% vs 60\%) and higher for $\mathrm{R}$ roots $(55 \% \mathrm{vs} 45 \%)$. This could appear contradictory with the higher taper rate of $\mathrm{S}$ roots compared to $\mathrm{R}$ roots. This higher segment taper is offset by, proportionally, an even higher ramification rate and by the combination of a higher ØLoss and lower MA/Br, which together increase the relative loss of diameter at each ramification point.

Taproots and sinkers (merged in T root type) were first considered separately in this study due to their specific position, growth direction and constraints (soil depth limit), and according to usual typologies. They are important for tree anchoring as they increase the resistance to windthrow (Danjon et al. 2005; Stokes et al. 1996). In the particular environment of dikes where this study was performed, always situated close to a water resource, $\mathrm{T}$ roots also have an essential role of looking for water in depth (Zanetti et al. 2014; Zanetti et al. 2011). However, from an architectural point of view, T roots appear simply as a special case of S roots, which may indicate that both types share some of their main functions and constraints. $\mathrm{T}$ and $\mathrm{S}$ roots did not differ for most architectural parameters including tapering or branching rates, even when split in sub-groups by size or material. Indeed, the few differences observed between these two types in our sample, including in the distribution of tapering and branching rate values (Fig. 4) can be attributed to the larger mean diameter of $\mathrm{T}$ roots and their capacity to be sometimes out of proportion compared to all other roots. They could also be attributed to the specific role and function of the main taproot as origin and focal point of the whole root system (Zobel and Waisel 2010). Finally, T roots, a type coming from classical root typologies, can be merged in the new $S$ type for architectural analyses.

The clear difference between $\mathrm{S}$ and $\mathrm{R}$ roots is probably related to different functions, not only to differences in soil condition around the trees: by focusing on sites with homogeneous materials, this study factors out the main effects of environmental heterogeneity on root growth (Hutchings and John 2004). Major roots emerging directly from the stump and from the taproot, and structuring the root system of adult trees, establish as dominant roots in 
the first few years (Coutts and Lewis 1983; Valdes-Rodriguez et al. 2013). As the architecture of R and S roots is extremely different and can hardly change with time, the two types are probably present since the early stages of root system development. Thus their initial proportion could be determined genetically (Cordoba-Rodriguez et al. 2011; Poot and Lambers 2008; Tomlinson et al. 2012), their relative development and survival being later determined by environmental constraints. The same combination of interacting genetic and environmental controls (Zhang et al. 2013) may drive the development of branches born from these early major roots, and of new roots appearing later on the stump and taproot (Forde 2009).

Running roots are tailored for exploring remote environments, to access distant water and nutrient resources. At the same time, they act as guys under tension to hold adult trees (Danjon et al. 2005). This role is accentuated by a faster growth in a preferential direction in windy places and on steep slopes (Danjon et al. 2013b; Sun et al. 2008; Tamasi et al. 2005). Tree root systems tend to have a larger span than their aerial part in poor environments where resources are scarce or unevenly distributed, thus requiring the exploration of a large area to sustain tree growth and survival (Moreno et al. 2005; Schenk and Jackson 2002). This is consistent with the significantly longer $\mathrm{R}$ roots found in coarse and poor materials compared with fine and richer materials in this study, and to the preferential development of long and big $\mathrm{R}$ roots downward the slopes of large dikes to reach the river or channel (Zanetti et al. 2014).

In coarse material, $S$ roots may be devoted to the exploration and exploitation of locally richer or more humid zones. The multiplication of highly ramified roots where resources are concentrated has been frequently described in heterogeneous environments and irrigated fields (George et al. 1997; Hodge 2004; Soar and Loveys 2007; Sokalska et al. 2009). This may explain why the distribution of S roots in coarse material does not follow a specific pattern: $\mathrm{S}$ roots, and sinkers which are very similar in their architecture, are found at all levels of root system hierarchy, as first order laterals on the stump as well as irregularly distributed along $\mathrm{R}$ roots. They probably develop opportunistically in appropriate microsites within the globally coarse material. Such a plasticity has been reported for a homogeneous soil texture due to spatial and temporal variations in nutrients availability (Mou et al. 2013). S roots are also found in fine material, more homogeneous and richer than coarse material. Their distribution could be linked to smaller but significant variations of water or nutrient availability or, simply, to the regular production of such roots by the plant according to a genetic determinism, to spatially optimize resources uptake and to guard preventively against all eventualities. Whatever the material, they present the same architectural characteristics and length for a given diameter, indicating that they probably play the same role.

The fact that most branches are of the same type than their mother axis means that some strong determinism may exist at the level of the whole root. This is partly linked in our case to the relative homogeneity of the material at the level of studied root systems, and therefore at the level of each root. Internal mechanism of remote control can also drive root development (Forde and Lorenzo 2001). However, the presence of $\mathrm{S}$ roots as branches of $\mathrm{R}$ roots as previously discussed as well as the observation of some $\mathrm{R}$ roots among the branches of $\mathrm{S}$ roots proves the high flexibility and opportunism of tree root system, independently from tree species in studied sites.

\section{3 - Indicators of the relationships between root mother axis and its branches}

The P ratio was designed to test the pipe model hypothesis (Mandelbrot 1983; Shinozaki et al. 1964a; Shinozaki et al. 1964b). The hypothesis is that $\mathrm{P}$ should be close to 1 and constant with root size or position in the root system (Van Noordwijk et al. 1994). This means that the root cross sectional area (CSA) of the main axis before a ramification should be shared after branching by the main axis and its branches with no loss of total CSA. In our results, significant variations of $\mathrm{P}$ exist according to root type, root size and material, although mean values by classes of these variables are close to each other and do not differ from 1 by more than $7 \%$. The range of variations increases when considering subgroups of roots combining root type, size and material: $\mathrm{P}$ reaches values as low as 0.87 (RL.c) or 0.88 (L.f) and as high as 1.09 (TB.f). Thus, our detailed results do not support the pipe model hypothesis for individual roots, although the hypothesis remains acceptable as a general law at root system scale. In order to reconstruct accurately tree root architecture from proximal diameter and branching rate with root models, the $\mathrm{P}$ ratio should vary along roots with their size and according to root type, as already suggested by Kalliokoski et al. (2010).

In this context, both original ratios we tested in this study and their variants (ØLoss, Ø2 $\mathrm{Loss}, \mathrm{Ma} / \mathrm{Br}, \mathrm{Ma} / \mathrm{Br}^{2}$ and $\mathrm{Ma} / \mathrm{Br}_{\text {sing }}$ ) bring new information, being more discriminant than $\mathrm{P}$ for some of the subgroups of roots: for example, $\mathrm{T}$ and $\mathrm{S}$ roots do not differ for $\mathrm{P}$ but they differ for $\mathrm{Ma} / \mathrm{Br}_{\text {sing. }} \mathrm{S}$ and $\mathrm{R}$ roots as well as I and $\mathrm{L}$ roots do not differ for $\mathrm{P}$ on fine material but they differ for nearly all variants of $\varnothing$ Loss and $\mathrm{Ma} / \mathrm{Br}$. When compared to each other, these new ratios also highlight different significant variations between subgroups. As shown by the comparison between $\mathrm{R}$ and $\mathrm{S}$ roots at the beginning of the discussion, the tradeoff between segment taper and ramification patterns in the explanation of the whole root tapering rate is easier to understand when ØLoss and $\mathrm{Ma} / \mathrm{Br}$ are considered.

As a whole, this set of parameters added to $\mathrm{P}$ proves that there are real architectural differences between roots according to their size and type. Secondarily it shows the plasticity of root types according to soil material, 
mainly for $\mathrm{R}$ roots. These results are consistent with those of Richardson et al. (2003), who demonstrated that branching and architectural parameters are variable with root size and proximal diameter for adult Douglas fir, although these differences are buffered at the scale of a whole root system. Danjon et al. (2013a) confirmed that root tapering rate and segment taper greatly differ between distal shallow roots and sinkers for Pinus pinaster, in accordance with Kalliokoski et al. (2010) who found differences in the P ratio between these two types of roots for three species of boreal forest.

\section{4 - Influence of soil material}

The main difference in root development according to material was found for R roots, 46 to $92 \%$ longer on coarse than on fine material, while $\mathrm{S}$ and $\mathrm{T}$ roots did not differ in length for a given diameter (Table 4). Zanetti et al. (2014) already demonstrated from whole root system statistics that roots were longer on coarse material for a given proximal diameter. Root system heterogeneity is therefore higher on coarse material.

Branching rate tends to diminish with increasing root size, this trend being limited to fine materials and, in this case, particularly marked between the classes intermediate and big (Fig. 7). Natural pruning occurs in fine material: the competition between roots may select progressively the most efficient among the many ones which appeared and developed during the first years or were formed later (Forde 2009), as resources are not a-priori limiting this number. In coarse, drained and poor materials, where sites with available resources are rare, root selection and self-pruning probably happen far earlier. This may explain the lower branching rate for little and intermediate roots compared to fine material. But later, the few successful roots occupying a suitable soil niche survive easier to ageing as they do not compete with other roots, which could explain the similar branching rate whatever root size in coarse material. Accordingly, a higher branching rate on richer sites was described by Kalliokoski et al. (2008) for Betula pendula in boreal forest, along with longer roots on coarse material, and indirectly confirmed for this species and two conifers (Picea abies and Pinus sylvestris) showing both smaller segments and a higher frequency of branching events with several (3 to 4) branches.

Very small but significant differences between materials exist for $\mathrm{P}$ and $\varnothing$ Loss $(\mathrm{c}<\mathrm{f})$, not for $\mathrm{MA} / \mathrm{Br}(\mathrm{Table} 6)$. Thus, the lower ØLoss explains most of the differences between materials for $\mathrm{P}$. When root types or size classes are split by material, and in the most detailed sub-groups (Type-Size-Mat analyses, table B.3), differences between materials for $\mathrm{P}$ and $\varnothing$ Loss are mainly linked to consistent variations within R roots (R.c < R.f), and always small within $\mathrm{S}$ and $\mathrm{T}$ subgroups, showing changes in their sign.

\section{5 - CONCLUSION AND PROSPECTS}

From a set of variables and ratios describing root architecture, we demonstrated the existence of two types of roots (short and running) on many tree species and in two contrasting soil materials. These types are important as they determine root system functionalities, shared by all studied species. Revisiting existing datasets and using these new types for other species and in different site conditions will help confirming their position as whether (i) the two ends of a continuous distribution or conversely, (ii) two functional types with clear differences but overlapping in their branching patterns due to root plasticity to environmental constraints and variations of this patterns with root size. The new parameters, ØLoss and $\mathrm{Ma} / \mathrm{Br}$, we tested successfully to study the relationship between root axes and their branches, may help modelling and describing more accurately root architecture, but could also be used to study tree aerial architecture. Some generic root traits and their evolution with root size which were highlighted in this paper seem to be common to many species, and to respond to environmental constraints more than to genetic determinisms. Species differences might be more relevant on the whole root level.

\section{Acknowledgements}

The authors are indebted to Caroline Brunel from IMBE for her help in multivariate analyses, to Frédéric Danjon for his comments and suggestions from early stages of this study, to many colleagues, technicians and students who contributed in data collection during 12 years of difficult field campaigns and in lab work, and particularly to Willy Martin, Roland Estève, Christian Ripert, Olivier Chandioux, Gaylord Doirat, Pierre-Jean Moundy, David Fiorese, Sophie Ferrat, Sebastien Tourrette and Geoffrey Blanc. This study was funded by Irstea, Provence-Alpes-Côte d'Azur region (PHD grant), the French National Research Agency (ANR - ERINOH project), by dike managers (EDF, CNR, AD Isère-Drac-Romanche, DDT Nièvre, SMAVD, Chambery Métropole, Conseil Général de l'Isère) who hired the technical staff and material to cut trees, extract root systems and remediate damages to studied sites, and the Labex OT-Med ( $\mathrm{n}^{\circ}$ ANR-11-LABX-0061) through a PHD grant. This work is a contribution to the Labex OT-Med funded by the French Government «Investissements d'Avenir» through the A*MIDEX project ( ${ }^{\circ}$ ANR-11-IDEX-0001-02) and to ECCOREV research Federation. 


\section{Annex:}

Table A: Comparison with Nemenyi test for root tapering and branching rates and segment taper, according to simultaneously root types $(T=$ taproots, $S=$ shorts roots, $R=$ running roots), root size $(B=$ big, $I=$ intermediate, $L=$ little) and Material ( $c=$ coarse, $f=$ fine). Groups sharing the same letter for a given variable did not differ statistically. For segment taper, differences were sometimes more linked to the median than to the mean, due to a very asymmetrical distribution and outliers. Lines highlighted in grey have too low numbers and were not included in the statistical analyses. Fig. 7 crosses tapering and branching rates for all groups of this table.

\begin{tabular}{|c|c|c|c|c|c|}
\hline \multicolumn{3}{|c|}{ Root tapering Rate $(\mathrm{cm} / \mathrm{m})$} & \multicolumn{3}{|c|}{ Branching rate $(\mathrm{nb} / \mathrm{m})$} \\
\hline Type & Mean & Groups & Type & Mean & Groups \\
\hline TB.f & 13.58 & $\mathrm{a}$ & TI.f & 11.37 & \\
\hline TB.c & 10.14 & $\mathrm{a}$ & SL.f & 10.22 & $\mathrm{a}$ \\
\hline SB.f & 8.03 & $\mathrm{a}$ & TB.f & 9.58 & $\mathrm{a}$ \\
\hline SB.c & 7.62 & $\mathrm{a}$ & SI.f & 9.28 & \\
\hline SI.f & 3.5 & $\mathrm{~b}$ & SL.c & 8.80 & \\
\hline SI.c & 3.48 & $\mathrm{~b}$ & SB.c & 7.62 & $\mathrm{a}$ \\
\hline RB.f & 3.13 & $\mathrm{~b}$ & TB.c & 7.12 & $\mathrm{a}$ \\
\hline RB.c & 2.55 & b & SI.c & 7.12 & $\mathrm{a}$ \\
\hline TI.f & 2.53 & & SB.f & 6.42 & $\mathrm{a}$ \\
\hline SL.f & 1.57 & & RL.f & 5.50 & \\
\hline SL.c & 1.47 & & RI.f & 4.39 & \\
\hline RI.f & 1.35 & $\mathrm{c}$ & RL.c & 3.77 & b \\
\hline RI.c & 1.05 & c & RB.c & 3.27 & $b$ \\
\hline RL.f & 0.53 & & RI.c & 3.02 & b \\
\hline RL.c & 0.38 & & RB.f & 2.78 & $\mathrm{~b}$ \\
\hline
\end{tabular}

\begin{tabular}{|l|r|l|}
\hline \multicolumn{3}{|c|}{ Segment taper $(\mathrm{cm} / \mathrm{m})$} \\
\hline Type & Mean & \multicolumn{1}{|c|}{ Groups } \\
\hline SB.f & 2.85 & $\mathrm{a}$ \\
SB.c & 2.56 & $\mathrm{a}$ \\
SI.f & 1.57 & $\mathrm{~b}$ \\
TB.f & 2.25 & $\mathrm{~b} \mathrm{c}$ \\
TB.c & 2.16 & $\mathrm{~b} \mathrm{c}$ \\
SI.c & 1.46 & $\mathrm{~b} \mathrm{c}$ \\
RB.f & 1.38 & $\mathrm{~b} \mathrm{c}$ \\
SL.f & 1.06 & \\
TI.f & 0.92 & $\mathrm{c} \mathrm{d}$ \\
RI.f & 0.82 & $\mathrm{c} \mathrm{d}$ \\
SL.c & 0.73 & $\mathrm{c} \mathrm{d}$ \\
RB.c & 0.86 & $\mathrm{~d} \mathrm{e}$ \\
RI.c & 0.50 & $\mathrm{e}$ \\
RL.f & 0.39 & $\mathrm{e}$ \\
RL.c & 0.28 & $\mathrm{e}$ \\
\hline
\end{tabular}


Tables B: Comparison of the mean values of $P$ and all variants of $\varnothing$ Loss and $M a / B r$ for the Material types ( $c=$ coarse, $f=$ fine $)$, root size $(B=$ big, $I=$ intermediate, $L=$ little $)$, root types $(T=$ taproots, $S=$ shorts roots, $R=$ running roots) and their combinations by two or three. Groups sharing the same letter for each test did not differ significantly according to the Nemenyi test.

Table B.1: Comparison between separately materials, root size classes and root types

\begin{tabular}{|c|c|c|c|c|}
\hline \multirow{8}{*}{$a$} & \multirow{2}{*}{$\frac{+}{\pi}$} & c & 1.02 & $a$ \\
\hline & & $f$ & 1.04 & b \\
\hline & \multirow{3}{*}{$\stackrel{N}{N}$} & B & 1.04 & $a$ \\
\hline & & 1 & 1.02 & b \\
\hline & & $\mathrm{L}$ & 0.96 & C \\
\hline & \multirow{3}{*}{$\sum_{\unrhd}^{0}$} & $T$ & 1.07 & $a$ \\
\hline & & $S$ & 1.06 & $a$ \\
\hline & & $\mathrm{R}$ & 1.00 & b \\
\hline
\end{tabular}

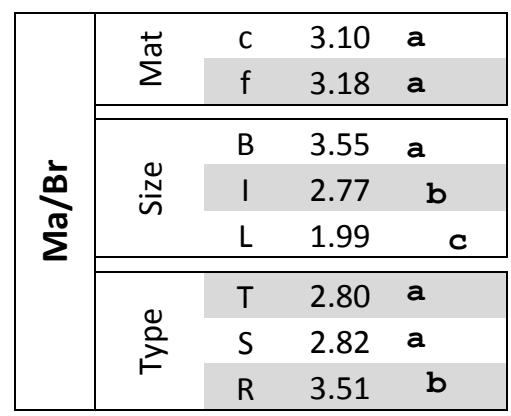

\begin{tabular}{|c|c|c|c|c|}
\hline \multirow{8}{*}{ 气ू } & \multirow{2}{*}{$\sum^{\frac{\pi}{2}}$} & C & 0.23 & $a$ \\
\hline & & $f$ & 0.25 & b \\
\hline & \multirow{3}{*}{$\stackrel{N}{N}$} & B & 0.24 & $a$ \\
\hline & & I & 0.24 & $a$ \\
\hline & & $\mathrm{L}$ & 0.18 & $b$ \\
\hline & \multirow{3}{*}{$\sum_{i}^{0}$} & $\bar{T}$ & 0.27 & $a$ \\
\hline & & $S$ & 0.28 & a \\
\hline & & $\mathrm{R}$ & 0.19 & $b$ \\
\hline
\end{tabular}

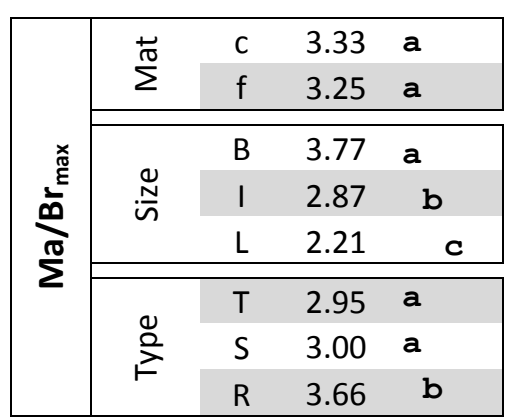

\begin{tabular}{|c|c|c|c|c|}
\hline \multirow{8}{*}{ 气̆ } & \multirow{2}{*}{$\stackrel{\pi}{\pi}$} & C & 1.20 & a \\
\hline & & $f$ & 1.27 & $b$ \\
\hline & \multirow{3}{*}{$\stackrel{N}{N}$} & B & 1.35 & a \\
\hline & & I & 1.14 & b \\
\hline & & $L$ & 0.79 & C \\
\hline & \multirow{3}{*}{$\sum_{1}^{0}$} & $\mathrm{~T}$ & 1.25 & $a$ \\
\hline & & $S$ & 1.39 & a \\
\hline & & $\mathrm{R}$ & 1.08 & b \\
\hline
\end{tabular}

\begin{tabular}{|c|c|c|c|c|}
\hline \multirow{8}{*}{ 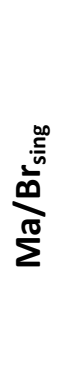 } & \multirow{2}{*}{$\sum^{\pi}$} & C & 3.41 & $a$ \\
\hline & & $f$ & 3.40 & a \\
\hline & \multirow{3}{*}{$\stackrel{N}{N}$} & B & 3.99 & $a$ \\
\hline & & I & 2.92 & $b$ \\
\hline & & $\mathrm{L}$ & 2.09 & c \\
\hline & \multirow{3}{*}{$\sum_{1}^{0}$} & $\mathrm{~T}$ & 3.33 & $b$ \\
\hline & & $S$ & 3.10 & $a$ \\
\hline & & $\mathrm{R}$ & 3.69 & C \\
\hline
\end{tabular}


Tables B: Comparison of the mean values of $P$ and all variants of $\varnothing$ Loss and $\mathrm{Ma} / \mathrm{Br}$ for the Material types $(c=$ coarse, $f=$ fine $)$, root size $(B=$ big, $I=$ intermediate, $L=$ little $)$, root types $(T=$ taproots, $S=$ shorts roots, $R=$ running roots) and their combinations by two or three. Groups sharing the same letter for each test did not differ significantly according to the Nemenyi test.

Table B.2: Comparison between groups of roots sorted by type and material (Type-Mat) or by Size and material (Size-Mat).

\begin{tabular}{|c|ccc|ccc|}
\cline { 2 - 5 } \multicolumn{1}{c|}{} & \multicolumn{3}{|c|}{ Type-Mat } & \multicolumn{3}{c|}{ Size-Mat } \\
\hline \multirow{1}{*}{ o-c } & 1.05 & $\mathbf{a}$ & B-c & 1.04 & $\mathbf{a}$ \\
S-c & 1.06 & $\mathbf{a}$ & I-c & 1.02 & b \\
R.c & 0.98 & b & L.c & 0.90 & c \\
T.f & 1.08 & $\mathbf{a}$ & B.f & 1.05 & $\mathbf{a}$ \\
S.f & 1.05 & $\mathbf{a}$ & I.f & 1.03 & $\mathbf{a b}$ \\
R.f & 1.02 & $\mathbf{a}$ & L.f & 0.88 & bc \\
\hline
\end{tabular}

\begin{tabular}{|c|c|c|c|c|c|c|}
\hline & \multicolumn{3}{|c|}{ Type-Mat } & \multicolumn{3}{|c|}{ Size-Mat } \\
\hline \multirow{6}{*}{$\frac{\grave{\Phi}}{\sum^{\frac{\pi}{\Sigma}}}$} & $T-c$ & 2.85 & $a b$ & B-C & 3.63 & a \\
\hline & S-C & 2.83 & b & I-C & 2.55 & C \\
\hline & R.C & 3.41 & $a$ & L.C & 1.85 & $d$ \\
\hline & T.f & 2.76 & $b$ & B.f & 3.41 & $a b$ \\
\hline & S.f & 2.80 & b & I.f & 3.03 & $b$ \\
\hline & R.f & 3.64 & $a$ & L.f & 2.31 & cd \\
\hline
\end{tabular}

\begin{tabular}{|c|c|c|c|c|c|c|}
\hline \multirow{6}{*}{$\stackrel{\tilde{o}}{\stackrel{\vec{Q}}{\alpha}}$} & T.C & 0.26 & $a b$ & B.C & 0.23 & b \\
\hline & S.C & 0.30 & $a$ & I.C & 0.24 & b \\
\hline & R.c & 0.17 & C & L.C & 0.20 & C \\
\hline & T.f & 0.29 & $a$ & B.f & 0.26 & $a$ \\
\hline & S.f & 0.27 & $a$ & I.f & 0.23 & b \\
\hline & R.f & 0.21 & b & L.f & 0.19 & C \\
\hline
\end{tabular}

\begin{tabular}{|c|c|c|c|c|c|c|}
\hline \multirow{6}{*}{ 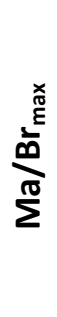 } & T.C & 3.07 & $a b$ & B.C & 3.97 & $a$ \\
\hline & S.C & 3.05 & b & I.C & 2.64 & C \\
\hline & R.C & 3.66 & $a$ & L.C & 2.08 & d \\
\hline & T.f & 2.84 & b & B.f & 3.44 & $b$ \\
\hline & S.f & 2.91 & b & I.f & 3.14 & $b$ \\
\hline & R.f & 3.66 & $a$ & L.f & 2.48 & cd \\
\hline
\end{tabular}

\begin{tabular}{|c|c|c|c|c|c|c|}
\hline \multirow{6}{*}{ 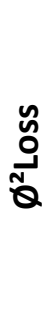 } & T.c & 1.16 & $a b$ & B.C & 1.32 & $a$ \\
\hline & S.C & 1.43 & $a$ & I.C & 1.11 & $b$ \\
\hline & R.C & 0.98 & C & L.C & 0.71 & C \\
\hline & T.f & 1.32 & a & B.f & 1.39 & a \\
\hline & S.f & 1.31 & a & I.f & 1.18 & $a b$ \\
\hline & R.f & 1.23 & $b$ & L.f & 0.95 & bc \\
\hline
\end{tabular}

\begin{tabular}{|c|c|c|c|c|c|c|}
\hline \multirow{6}{*}{ 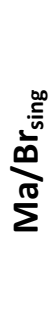 } & T.C & 3.33 & $a b$ & B.C & 4.12 & $a$ \\
\hline & S.C & 3.17 & b & I.C & 2.74 & C \\
\hline & R.C & 3.66 & $a$ & L.C & 2.00 & d \\
\hline & T.f & 3.32 & $a b$ & B.f & 3.79 & $\mathrm{~b}$ \\
\hline & S.f & 2.98 & b & I.f & 3.15 & C \\
\hline & R.f & 3.73 & $a$ & L.f & 2.25 & $\mathrm{~cd}$ \\
\hline
\end{tabular}


Tables B: Comparison of the mean values of $P$ and all variants of $\emptyset$ Loss and $\mathrm{Ma} / \mathrm{Br}$ for the Material types $(c=$ coarse, $f=$ fine $)$, root size $(B=$ big, $I=$ intermediate, $L=$ little $)$, root types $(T=$ taproots, $S=$ shorts roots, $R=$ running roots) and their combinations by two or three. Groups sharing the same letter for each test did not differ significantly according to the Nemenyi test.

Table B.3: Comparison between groups of roots sorted by type and size (Type-Size) and sorted by type, size and material (Type-Size-Mat). Some groups with very low numbers were not integrated in the analyses and their values are not displayed as they may not be representative. The two columns of letters of Type-Size-Mat are coming from a single Nemenyi test for each variable and must be considered together to compare concerned mean values.

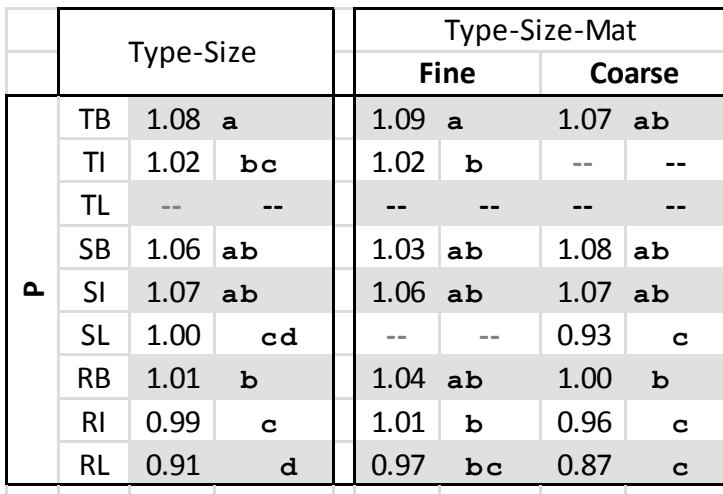

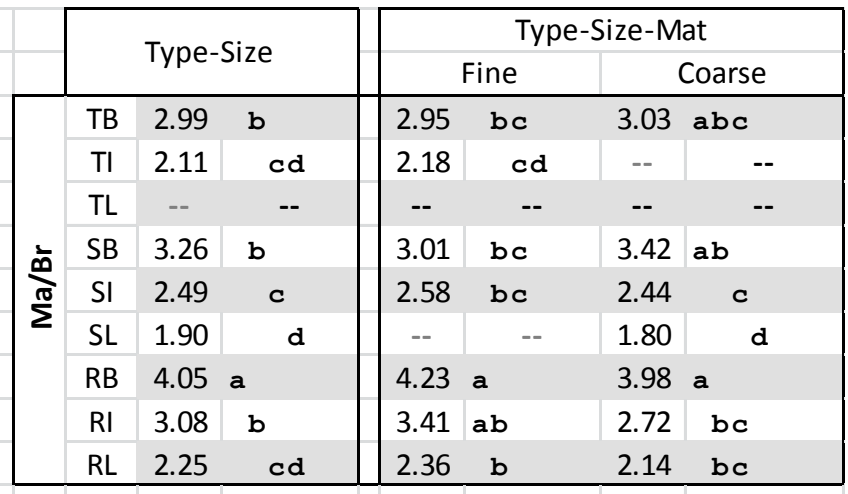

\begin{tabular}{|c|c|c|c|c|c|c|c|}
\hline \multirow{9}{*}{ ڤ̆ } & TB & 0.28 & $a$ & 0.30 & $a b$ & 0.26 & $a b$ \\
\hline & $\mathrm{TI}$ & 0.24 & b & 0.22 & $a b$ & -- & -- \\
\hline & TL & -- & -- & -- & -- & -- & -- \\
\hline & SB & 0.28 & a & 0.27 & $a b$ & 0.29 & $a b$ \\
\hline & SI & 0.29 & $a$ & 0.27 & $a b$ & 0.30 & $a$ \\
\hline & SL & 0.24 & b & -- & -- & 0.24 & b \\
\hline & $\mathrm{RB}$ & 0.19 & b & 0.23 & $a b$ & 0.17 & c \\
\hline & RI & 0.19 & b & 0.21 & bc & 0.17 & c \\
\hline & $\mathrm{RL}$ & 0.14 & $b$ & 0.18 & bc & 0.10 & c \\
\hline
\end{tabular}

\begin{tabular}{|c|c|c|c|c|c|c|c|}
\hline \multirow{9}{*}{ 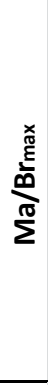 } & TB & 3.12 & $\mathrm{~b}$ & 3.00 & $\mathrm{~cd}$ & 3.24 & $a b c$ \\
\hline & $\mathrm{Tl}$ & 2.39 & c & 2.45 & de & -- & -- \\
\hline & $\mathrm{TL}$ & -- & -- & -- & -- & -- & -- \\
\hline & SB & 3.46 & $a b$ & 3.08 & bcd & 3.70 & $a b$ \\
\hline & SI & 2.64 & c & 2.76 & $\mathrm{~cd}$ & 2.58 & de \\
\hline & SL & 2.14 & $d$ & -- & -- & 2.07 & e \\
\hline & RB & 4.33 & a & 4.19 & $a b$ & 4.39 & $a$ \\
\hline & $\mathrm{RI}$ & 3.11 & $b$ & 3.46 & bc & 2.74 & $c d$ \\
\hline & $\mathrm{RL}$ & 2.40 & $c d$ & 2.55 & de & 2.26 & $\mathrm{de}$ \\
\hline
\end{tabular}

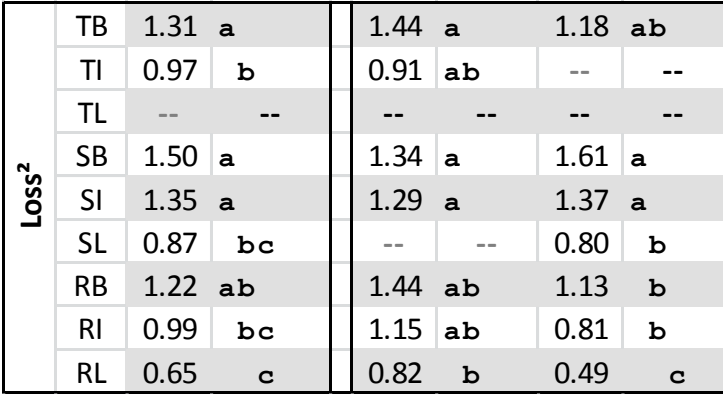

\begin{tabular}{|c|c|c|c|c|c|c|c|}
\hline \multirow{9}{*}{ 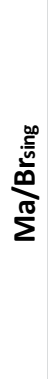 } & TB & \multicolumn{2}{|c|}{$3.68 \mathrm{ab}$} & \multicolumn{2}{|c|}{$3.82 \mathrm{ab}$} & \multicolumn{2}{|c|}{$3.56 \mathrm{ab}$} \\
\hline & $\mathrm{Tl}$ & 2.06 & de & 2.09 & $c d$ & -- & -- \\
\hline & $\mathrm{TL}$ & -- & -- & -- & -- & -- & -- \\
\hline & SB & 3.70 & b & 3.28 & $\mathrm{bc}$ & 3.99 & $a b$ \\
\hline & $\mathrm{SI}$ & 2.67 & $d$ & 2.72 & c & 2.65 & c \\
\hline & SL & 1.98 & e & -- & -- & 1.89 & d \\
\hline & RB & 4.38 & a & 4.33 & $a b$ & 4.40 & a \\
\hline & $\mathrm{RI}$ & 3.20 & c & 3.49 & bc & 2.87 & bc \\
\hline & $\mathrm{RL}$ & 2.31 & de & 2.31 & $c d$ & 2.30 & $\mathrm{~cd}$ \\
\hline
\end{tabular}

\section{BIBLIOGRAPHY}

Atger C (1991) L'architecture racinaire est-elle influencée par le milieu? L'arbre, biologie et developpement hors série:71-84

Atger C, Edelin C (1994a) Premières données sur l'architecture comparée des systèmes racinaires et caulinaires Can J Bot 72:963-975

Atger C, Edelin C (1994b) Sratégie d'occupation du milieu souterrain par les systèmes racinaires des arbres Ecologie 49:343-356

Barthélémy D, Blaise F, Fourcaud T, Nicolini E (1995) Modélisation et simulation de l'architecture des arbres : bilan et perspectives Revue Forestière Française 47:71-96

Barthelemy D, Caraglio Y (2007) Plant architecture: A dynamic, multilevel and comprehensive approach to plant form, structure and ontogeny Ann Bot 99:375-407 
Bodner G, Leitner D, Nakhforoosh A, Sobotik M, Moder K, Kaul H-P (2013) A statistical approach to root system classification Frontiers in plant science 4:doi: 10.3389/fpls.2013.00292

Collet C, Lof M, Pages L (2006) Root system development of oak seedlings analysed using an architectural model. Effects of competition with grass Plant Soil 279:367-383 doi:10.1007/s11104-005-2419-9

Cordoba-Rodriguez D, Vargas-Hernandez JJ, Lopez-Upton J, Munoz-Orozco A (2011) Root growth in young plants of Pinus pinceana Gordon in response to soil moisture Agrociencia 45:493-506

Coutts MP, Lewis GJ (1983) When is the structural root system determined in Sitka spruce? Plant Soil:155-160

Danjon D, Fourcaud, Bert (2005) Root architecture and wind-firmness of mature Pinus pinaster New Phytol 168:387-400

Danjon F, Bert D, Godin C, Trichet P (1999a) Structural root architecture of 5-year-old Pinus pinaster measured by 3D digitising and analysed with AMAPmod Plant Soil 217:49-63

Danjon F, Caplan JS, Fortin M, Meredieu C (2013a) Descendant root volume varies as a function of root type: estimation of root biomass lost during uprooting in Pinus pinaster Frontiers in Plant Science 4 doi:10.3389/fpls.2013.00402

Danjon F, Fourcaud T, Bert D (2005) Root architecture and wind-firmness of mature Pinus pinaster New Phytol 168:387-400 doi:10.1111/j.1469-8137.2005.01497.x

Danjon F, Khuder H, Stokes A (2013b) Deep Phenotyping of Coarse Root Architecture in R. pseudoacacia Reveals That Tree Root System Plasticity Is Confined within Its Architectural Model PLoS One 8 doi:10.1371/journal.pone.0083548

Danjon F, Reubens B (2008) Assessing and analyzing 3D architecture of woody root systems, a review of methods and applications in tree and soil stability, resource acquisition and allocation Plant Soil 303:1 34 doi:10.1007/s11104-007-9470-7

Danjon F, Sinoquet H, Godin C, Colin F, Drexhage M (1999b) Characterisation of structural tree root architecture using 3D digitising and AMAPmod software Plant Soil 211:241-258 doi:10.1023/a:1004680824612

Dunbabin V et al. (2013) Modelling root-soil interactions using three-dimensional models of root growth, architecture and function Plant Soil 372:93-124 doi:10.1007/s11104-013-1769-y

Dupuy F, Stokes, Danjon (2005) A density-based approach for the modelling of root architecture: application to Maritime pine (Pinus pinaster Ait.) root systems J Theor Biol 236:323-334

Eis S (1974) Root system morphology of Western Hemlock, Western Red Cedar, and Douglas-Fir Canadian Journal of Forest Research-Revue Canadienne De Recherche Forestiere:28-38

Fitter AH (1987) An Architectural Approach to the Comparative Ecology of Plant Root Systems New Phytol 106:61-77 doi:10.2307/2433011

Fitter AH, Stickland TR (1992) Fractal characterization of root system architecture Funct Ecol 6:632-635

Fitter AH, Stickland TR, Harvey ML, Wilson GW (1991) Architectural analysis of plant root systems 1. Architectural correlates of exploitation efficiency New Phytol 118:375-382

Forde B, Lorenzo H (2001) The nutritional control of root development Plant Soil 232:51-68 doi:10.1023/a:1010329902165

Forde BG (2009) Is it good noise? The role of developmental instability in the shaping of a root system J Exp Bot 60:3989-4002 doi:10.1093/jxb/erp265

Foussadier R (2003) Les systèmes racinaires des arbres de la ripisylve : effets des contraintes physiquues et exemples. In: IDF (ed) Les forêts riveraines des cours d'eau, écologie, fonctions et gestion. Paris, pp 124-133

George E, Seith B, Schaeffer C, Marschner H (1997) Responses of Picea, Pinus and Pseudotsuga roots to heterogeneous nutrient distribution in soil Tree Physiol 17:39-45

Hodge A (2004) The plastic plant: root responses to heterogeneous supplies of nutrients New Phytol 162:9-24 doi:10.1111/j.1469-8137.2004.01015.x 
Hutchings MJ, John EA (2004) The Effects of Environmental Heterogeneity on Root Growth and Root/Shoot Partitioning Ann Bot 94:1-8 doi:10.1093/aob/mch111

Kalliokoski T, Nygren P, Sievanen R (2008) Coarse root architecture of three boreal tree species growing in mixed stands Silva Fenn 42:189-210

Kalliokoski T, Sievanen R, Nygren P (2010) Tree roots as self-similar branching structures: axis differentiation and segment tapering in coarse roots of three boreal forest tree species Trees-Struct Funct 24:219-236 doi:10.1007/s00468-009-0393-1

Köstler J-N, Brueckner E, Bibelriether H (1968) Die Wurzeln der Waldbäume. Untersuchung zur Morphologie der Waldbäume in Mitteleuropa. Paul Parey, Hamburg

Mandelbrot BB (1983) The fractal geometry of nature. W.H. Freeman and Co., New York,

Moreno G, Obrador JJ, Cubera E, Dupraz C (2005) Fine root distribution in Dehesas of Central-Western Spain Plant Soil 277:153-162

Mou P, Jones R, Tan Z, Bao Z, Chen H (2013) Morphological and physiological plasticity of plant roots when nutrients are both spatially and temporally heterogeneous Plant Soil 364:373-384 doi:10.1007/s11104$012-1336-y$

Nemenyi PB (1963) Distribution-free multiple comparisons. Princeton University, New Jersey.

Nicoll BC, Berthier S, Achim A, Gouskou K, Danjon F, van Beek LPH (2006a) The architecture of Picea sitchensis structural root systems on horizontal and sloping terrain Trees-Struct Funct 20:701-712 doi:10.1007/s00468-006-0085-z

Nicoll BC, Gardiner BA, Rayner B, Peace AJ (2006b) Anchorage of coniferous trees in relation to species, soil type, and rooting depth Canadian Journal of Forest Research-Revue Canadienne De Recherche Forestiere 36:1871-1883 doi:10.1139/x06-072

Poot P, Lambers H (2008) Shallow-soil endemics: adaptive advantages and constraints of a specialized rootsystem morphology New Phytol 178:371-381 doi:10.1111/j.1469-8137.2007.02370.x

R Core Team (2010) R: A language and environment for statistical computing vol R Foundation for Statistical Computing. Vienna (Austria)

Richardson AD, Zu Dohna H (2003) Predicting root biomass from branching patterns of Douglas-fir root systems Oikos 100:96-104 doi:10.1034/j.1600-0706.2003.12081.x

Schenk HJ, Jackson RB (2002) The global biogeography of roots Ecol Monogr 72:311-328 doi:10.2307/3100092

Shinozaki K, Yoda K, Hozumi K, Kira T ( 1964a) A quantitative analysis of plant form: the pipe model theory. II. Further evidence for the theory and its application in forest ecology Japanese Journal of Ecology 14:133-139

Shinozaki K, Yoda K, Hozumi K, Kira T ( 1964b) A quantitative analysis of plant form: the pipe model theory. I. Basic analyses Japanese Journal of Ecology 14:97-105

Smit AL, Bengough AG (2000) Root characteristics : why and what to measure. In: Smit AL, Bengough AG (eds) Root methods : a hand book, vol 1. Springer, pp 1-20

Smit AL, Bengough AG, Engels C, Noordwijk M, Pellerin S, Geijn SC (2000) Root Methods. A Handbook. Springer Berlin Heidelberg,

Soar CJ, Loveys BR (2007) The effect of changing patterns in soil-moisture availability on grapevine root distribution, and viticultural implications for converting full-cover irrigation into a point-source irrigation system Aust J Grape Wine Res 13:2-13

Soethe N, Lehmann J, Engels C (2007) Root tapering between branching points should be included in fractal root system analysis Ecol Model 207:363-366 doi:10.1016/j.ecolmodel.2007.05.007

Sokalska DI, Haman DZ, Szewczuk A, Sobota J, Deren D (2009) Spatial root distribution of mature apple trees under drip irrigation system Agric Water Manag 96:917-924 doi:10.1016/j.agwat.2008.12.003

Stokes A, Ball J, Fitter AH, Brain P, Coutts MP (1996) An experimental investigation of the resistance of model root systems to uprooting Ann Bot 78:415-421 doi:10.1006/anbo.1996.0137 
Sun HL, Li SC, Xiong WL, Yang ZR, Cui BS, Tao Y (2008) Influence of slope on root system anchorage of Pinus yunnanensis Ecological Engineering 32:60-67 doi:10.1016/j.ecoleng.2007.09.002

Sutton RF, Tinus RW (1983) Root and root system terminology vol 24. Forest Science Monograph. Society of American Foresters, Bethesda (USA)

Tamasi E, Stokes A, Lasserre B, Danjon F, Berthier S, Fourcaud T, Chiatante D (2005) Influence of wind loading on root system development and architecture in oak (Quercus robur L.) seedlings Trees-Struct Funct 19:374-384 doi:10.1007/s00468-004-0396-x

Tomlinson KW et al. (2012) Biomass partitioning and root morphology of savanna trees across a water gradient J Ecol 100:1113-1121 doi:10.1111/j.1365-2745.2012.01975.x

Valdes-Rodriguez OA, Sanchez-Sanchez O, Perez-Vazquez A, Caplan JS, Danjon F (2013) Jatropha curcas L. Root Structure and Growth in Diverse Soils Sci World J doi:10.1155/2013/827295

Van Noordwijk M, Spek LY, Dewilligen P (1994) Proximal root diameter as predictor of total root size for fractal branching models. 1. Theory Plant Soil 164:107-117

Vercambre G, Pages L, Doussan C, Habib R (2003) Architectural analysis and synthesis of the plum tree root system in an orchard using a quantitative modelling approach Plant Soil 251:1-11

Wagner B, Gärtner H, Santini S, Ingensand H (2011) Cross-sectional interpolation of annual rings within a 3D root model Dendrochronologia 29:201-210

Wahid PA (2000) A system of classification of woody perennials based on their root activity patterns Agrofor Syst 49:123-130

Wilson BF ( 1975) Distribution of secondary thickening in tree root systems. In: Torrey JG, Clarkson DT (eds) The development and function of roots. Academic Press Inc., London, pp 197-219

Zanetti C, Vennetier M, Mériaux P (2014) Plasticity of tree root system structure in contrasting soil materials and environmental conditions Plant Soil:in press doi:10.1007/s11104-014-2253-Z

Zanetti C, Vennetier M, Mériaux P, Royet P, Dufour S, Provansal M (2008) L'enracinement des arbres dans les digues en remblai : étude des systèmes racinaires et impacts sur la sécurité des ouvrages Ingénieries - E A T 53:49-67

Zanetti C, Vennetier M, Mériaux P, Royet P, Provansal M, Blanc G (2011) Managing woody vegetation on earth dikes: risks assessment and maintenance solutions Procedia Environmental Sciences 9:196-200.

Zhang Y, Zhou Z, Yang Q (2013) Genetic variations in root morphology and phosphorus efficiency of Pinus massoniana under heterogeneous and homogeneous low phosphorus conditions Plant Soil 364:93-104 doi:10.1007/s11104-012-1352-y

Zobel RW, Waisel Y (2010) A plant root system architectural taxonomy: A framework for root nomenclature Plant Biosyst 144:507-512 doi:10.1080/11263501003764483 